\title{
Cloud manufacturing as a sustainable process manufacturing route
}

Oliver Fisher ${ }^{1}$, Nicholas Watson ${ }^{1}$, Laura Porcu ${ }^{2}$, Darren Bacon ${ }^{2}$, Martin Rigley ${ }^{2}$, Rachel L Gomes ${ }^{1 *}$

${ }^{1}$ Food, Water, Waste Research Group, Faculty of Engineering, University of Nottingham, University Park, Nottingham, NG7 2RD, United Kingdom

${ }^{2}$ Lindhurst Engineering Ltd., Midland Road, Sutton in Ashfield, Nottinghamshire, NG17 5GS, United Kingdom

Corresponding author

Author: Rachel L Gomes

Tel.: +44 1158468883 .

E-mail address: rachel.gomes@nottingham.ac.uk

\begin{abstract}
Cloud Manufacturing (CM) is a service oriented business model to share manufacturing capabilities and resources on a cloud platform. Manufacturing is under pressure to achieve cost and environmental impact reductions, as manufacturing becomes more integrated and complex. Cloud manufacturing offers a solution, as it is capable of making intelligent decisions to provide the most sustainable and robust manufacturing route available. Although CM research has progressed, a consensus is still lacking on the concepts within $\mathrm{CM}$ as well as applications and scope beyond discrete manufacturing.
\end{abstract}

The aim of this paper is to demonstrate how $\mathrm{CM}$ offers a more sustainable manufacturing future to the industry as a whole, before focusing specifically on the application to process manufacturing (e.g. food, pharmaceuticals and chemicals). This paper details the definitions, characteristics, architectures and previous case studies on CM. From this, the fundamental aspects of the CM concept are identified, along with an analysis of how the concept has progressed. A new, comprehensive CM definition is formulated by combining key concepts drawn from previous definitions and emphasizes $\mathrm{CM}$ potential for sustainable manufacturing.

Four key methods of how CM increases sustainability are identified: (1) collaborative design; (2) greater automation; (3) improved process resilience and (4) enhanced waste reduction, reuse and recovery. The first two key methods are common to both discrete and process manufacturing, however key methods ( 3 ) and (4) are more process manufacturing specific and application of CM for these has yet to be fully realised. Examples of how CM's characteristics may be utilised to solve various process manufacturing problems are presented to demonstrate the applications of $\mathrm{CM}$ to process manufacturing. Waste is an important consideration in manufacturing, with strong sustainability implications. The current focus has been on using CM for waste minimisation; however, process manufacturing offers waste as a resource (valorisation opportunities from diversifying co-products, reuse, recycle and energy recovery). Exploring CM's potential to characterise and evaluate alternative process routes for the valorisation of process manufacturing waste is considered for the first time. The specific limitations preventing CM adoption by process manufacturers are discussed. Finally, CM's place in the future of manufacturing is explored, including how it will interact with, and complement other emerging manufacturing technologies to deliver a circular economy and personalised products. 


\section{Keywords}

Cloud manufacturing, Circular economy, Process manufacturing, Resilient manufacturing, Waste valorization

\section{Contents}

Abstract .

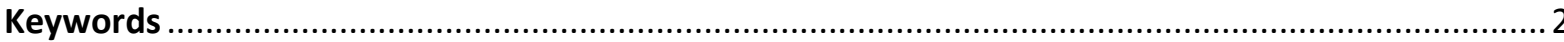

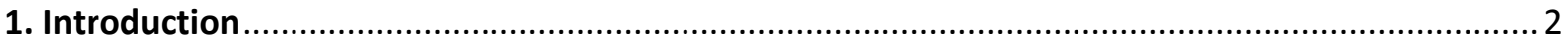

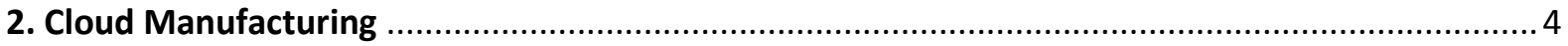

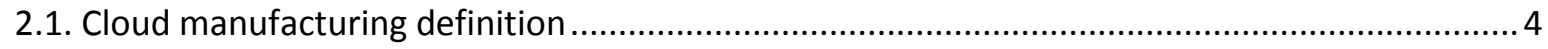

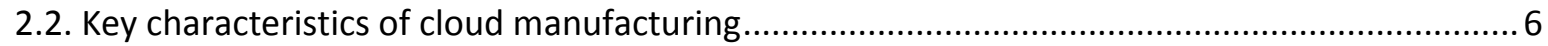

2.3. Cloud manufacturing frameworks, architectures and implementation .................................... 8

2.4. Case studies of cloud manufacturing's application ................................................................. 10

3. Cloud manufacturing as a route to sustainable manufacturing ................................................13

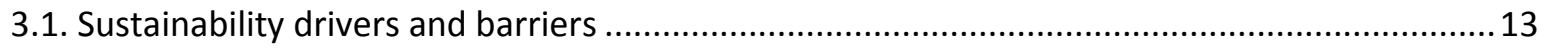

3.2. Cloud manufacturing enabling collaboration for innovative designs ......................................13

3.3. Greater automation from the adoption of cloud manufacturing systems ................................ 13

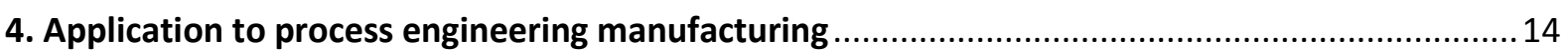

4.1. Difference between discrete and process manufacturing..................................................... 14

4.2. Application of collaborative design and greater automation to process manufacturing...........16

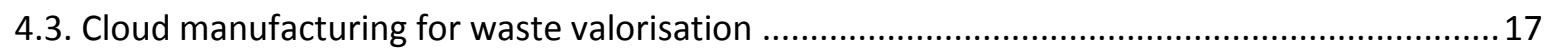

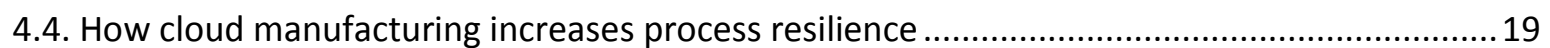

4.5. Examples of cloud manufacturing's application to process manufacturing ................................2

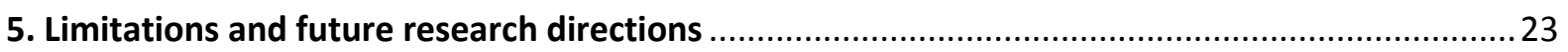

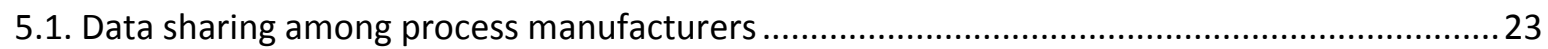

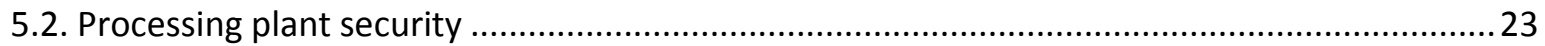

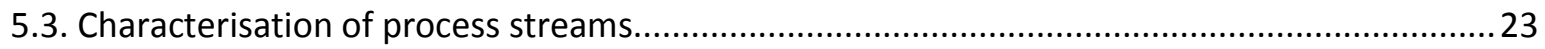

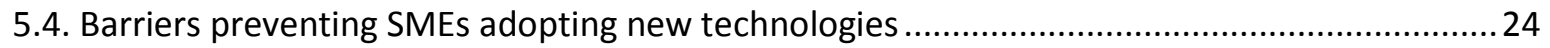

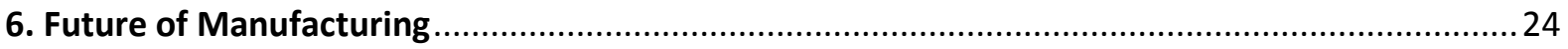

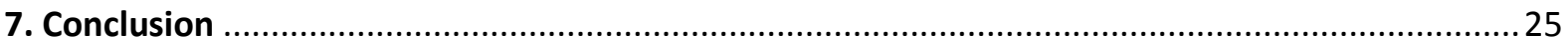

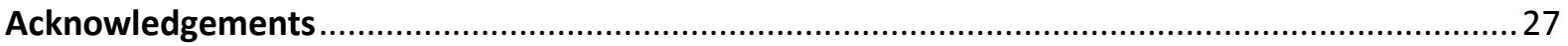

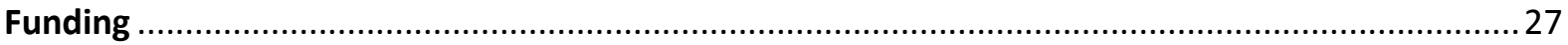

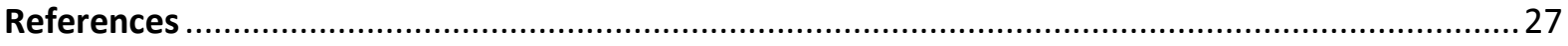

\section{Introduction}

Today's manufacturing sector includes a broad range of industries, from food and drink, pharmaceutical, automobile and aerospace, to computer and electronic product manufacturing. 
Manufacturing is a vital sector in society, irrespective of being a high or low-income economy. In previous decades the manufacturing sectors of the USA, Japan, the UK, France and Italy have lost global market shares due to pressure from China. The exception being Germany, which has instead increased exports to China and Asia [1]. This is in part due to Germany's Government support of the application of manufacturing technology. Since the 2008 recession, policymakers in the West have focused on rebalancing the economy away from the service sector towards manufacturing [2]. Manufacturing in the USA and the UK account for $12 \%$ and $10 \%$ of the country's gross domestic product (GDP) respectively [3]. Whereas, in Germany the manufacturing sector accounts for $23 \%$ of GDP [3]. This led to the German economy making a faster recovery. It is not only Western economies that are facing new manufacturing challenges. The recent trend has been for manufacturers to move to low-income economies to benefit from cheaper production costs. However, China's manufacturing growth is slowing due the rapid increase in the cost of human resources, materials and energy [3]. Governments are facing the further challenge of developing policies which support manufacturing, while maintaining their commitment made in Paris to lower carbon emissions [4]. There are also additional drivers such as the EU Waste Framework, which promotes the waste hierarchy with financial incentives to minimise and/or reuse wastes [5]. The circular economy has emerged as an alternative economic model that supports growth, while minimising environmental impacts from production and consumption. The Waste and Resources Action Program charity offers a clear definition of the circular model: "A circular economy is an alternative to a traditional linear economy (make, use, dispose) in which we keep resources in use for as long as possible, extract the maximum value from them whilst in use, then recover and regenerate products and materials at the end of each service life." [6]. To create a sustainable manufacturing future, new manufacturing models need to be explored that support this circular approach.

Various advanced manufacturing models have been proposed to achieve this [7-10]. A concurrent concept across these models is the idea of an increase in collaboration, automation, and knowledge and data sharing throughout the supply chain. As a result, the manufacturing process benefits from an increase in flexibility, resource efficiency, and customisation. Recently a new manufacturing paradigm called Cloud Manufacturing (CM) has emerged, which serves to act as a platform to deliver this vision [11]. Underlying the $\mathrm{CM}$ model is the concept of sharing manufacturing capabilities and resources on a cloud platform capable of making intelligent decisions to provide the most sustainable and robust manufacturing route available. Limitations in largely computer processing power, data collection and analytics, and security solutions have hindered the deployment of previous advanced manufacturing models. Cloud manufacturing however, has the advantage of utilising new technologies such as cloud computing, big data, and the Industrial Internet of Things (IloT, the industrial focus of the Internet of Things), enabling CM to overcome many of these previous limitations. Cloud manufacturing also has the potential to be a key component in the future manufacturing landscape. It complements emerging manufacturing processes, such as Additive Manufacturing (AM), to deliver consumer customised products via sustainable processes. Where AM utilises 3D design data to build up a component in layers by depositing material, it is more commonly known as 3D printing [12].

Several projects have investigated research themes and applications of CM. In 2009, China launched the National High-Tech Research and Development Programme to promote research related to CM [13]. Two of the earliest and most cited papers on CM came from China. Tao et al. established and illustrated the basic ideas of CM including architecture, definition, characteristics and benefits [14]. $\mathrm{Xu}$ analysed how cloud computing is changing manufacturing and defined the difference between cloud computing alongside manufacturing and $\mathrm{CM}$ [15]. Under the European Seventh Framework Programme the project ManuCloud was established. The ManuCloud project objective was to 
investigate and develop a cloud-based infrastructure to provide better support for on-demand manufacturing supply chains in the photovoltaic, organic lighting and automotive sectors [16]. There are now companies emerging which offer cloud-based services for manufacturing. For example, Plex Systems has developed the Plex Manufacturing Cloud, which is a software as a service (SaaS) enterprise resource planner (ERP) that manages the manufacturing process [17]. The software is designed to provide managers and engineers with real time access to production data. However, the full implications of CM have yet to be fully realised in industry. Industry 4.0 was first coined in Germany and refers to the digitisation of the manufacturing sector driven by huge increases in data volumes, computational power and increasing manufacturing plant connectivity [18]. Cloud manufacturing has potential to work within Industry 4.0 to exploit an on-demand access to a shared collection of manufacturing resources to form temporary, reconfigurable supply chains with enhanced efficiency, reduced production costs, and optimal resource allocation.

This paper shall aim to explain how CM may offer a route to sustainable process manufacturing. To achieve this effectively, this paper will address five key questions:

1. What is $\mathrm{CM}$, its key characteristics and what are the proposed frameworks and architectures for implementing CM?

2. How does $\mathrm{CM}$ offer a route to future sustainable manufacturing?

3. How does process manufacturing vary from discrete manufacturing?

4. What are the opportunities for $\mathrm{CM}$ to benefit process manufacturing?

5. What limitations specific to process manufacturing currently prevent the widespread adoption of $\mathrm{CM}$, and what future research is necessary to overcome these limitations?

\section{Cloud Manufacturing}

\subsection{Cloud manufacturing definition}

Cloud manufacturing's first definition emerged in 2010 [11]. However, since that publication CM has generated considerable research interest and there now exists a variety of definitions. Unfortunately, there has yet to be an agreed common definition. Even the nomenclature and abbreviations can vary from author to author. A selection of some of the first $\mathrm{CM}$ definitions to emerge are detailed in Table 1 , these definitions have since been commonly cited in recent publications on CM [19-25].

Table 1

Cloud manufacturing definitions arising from literature to date

\begin{tabular}{|c|c|}
\hline Definition & Author/s \\
\hline $\begin{array}{l}\text { "Cloud-based design and manufacturing (CBDM) refers to a product development } \\
\text { model that enables collective open innovation and rapid product development } \\
\text { with minimum cost through social networking and crowd-sourcing platforms } \\
\text { coupled with shared service pools of design, manufacturing resources and } \\
\text { components." }\end{array}$ & [26] \\
\hline $\begin{array}{l}\text { "Cloud manufacturing (CMfg) is a computing and service-oriented manufacturing } \\
\text { model developed from existing advanced manufacturing models (e.g., application } \\
\text { service providers, agile manufacturing, networked manufacturing, manufacturing } \\
\text { grids) and enterprise information technologies under the support of cloud } \\
\text { computing, the Internet of Things (loT), virtualization and service-oriented } \\
\text { technologies, and advanced computing technologies." }\end{array}$ & [14] \\
\hline $\begin{array}{l}\text { "Cloud-based design and manufacturing (CBDM) refers to a service-oriented } \\
\text { product development model in which service consumers are able to configure } \\
\text { products or services as well as reconfigure manufacturing systems through }\end{array}$ & [27] \\
\hline
\end{tabular}


Infrastructure-as-a-Service (laaS), Platform-as-a-Service (PaaS), Hardware-as-aService (HaaS), and Software-as-a-Service (SaaS) in response to rapidly changing customer needs. CBDM is characterised by on demand self-service, ubiquitous access to networked data, rapid scalability, resource pooling, and virtualisation. The types of deployment models include private, public, and hybrid clouds."

"Cloud manufacturing (CM) is a customer-centric manufacturing model that [28] exploits on-demand access to a shared collection of diversified and distributed manufacturing resources to form temporary, reconfigurable production lines with enhanced efficiency, reduced product lifecycle costs, and allow for optimal resource loading in response to variable-demand customer generated tasks." "Cloud manufacturing (CM) is a model for enabling ubiquitous, convenient, ondemand network access to a shared pool of configurable manufacturing resources (e.g., manufacturing software tools, manufacturing equipment, and manufacturing capabilities) that can be rapidly provisioned and released with minimal management effort or service provider interaction."

"A new service-oriented, high efficient and low consumptive, knowledge-based and intelligent networked agile manufacturing model and technology, allowing manufacturing resources and capabilities to be virtualized and transformed into on-demand services available to users through a product life cycle."

Each of these definitions prioritise different aspects of $\mathrm{CM}$; for example, service oriented manufacturing, product development, resource allocation or customer centric manufacturing. The chosen aspect normally reflects the possible application of $\mathrm{CM}$ that was being demonstrated and was therefore highlighted in the authors' definition. Despite the differences in these definitions, all contain common elements such as, network manufacturing, ubiquitous access, multi-tenancy, virtualisation, big data, everything-as-a-service, scalability, and resource pooling. These can be used to help define the fundamental principles and characteristics of $\mathrm{CM}$, which in turn give thought to how it can be utilised to achieve a sustainable manufacturing route.

To draw out the main themes, these definitions have been entered into a word cloud generator [30], the result of which is presented in Fig. 1. The word cloud highlights the following concepts: service oriented, on-demand, network, intelligent, access, knowledge based, shared pool, rapid, scalability, advance and virtualised. This paper proposes a comprehensive CM definition combining the highlighted concepts from all these definitions and emphasising CM potential for sustainable manufacturing.

"Cloud manufacturing is a service oriented manufacturing model that virtualises manufacturing resources and capabilities into on-demand services accessed through the manufacturing cloud. This transforms manufacturing supply lines to become temporary, and provide greater flexibility and scalability resulting in increased resilience and sustainability throughout the manufacturing process. Cloud manufacturing is a multi-tenant, intelligent, knowledge based platform that can provide sustainable solutions throughout the product and process life cycle via effective collaboration, data mining, and communication across a network of developers, manufacturers and consumers."

This definition, although comprehensive, is too long to easily bring to mind when asked what $\mathrm{CM}$ is. Therefore, a shortened definition is offered that captures the essence of CM. 
"The cloud manufacturing model is the concept of sharing manufacturing capabilities and resources on a cloud platform capable of making intelligent decisions to provide the most sustainable and robust manufacturing route available."

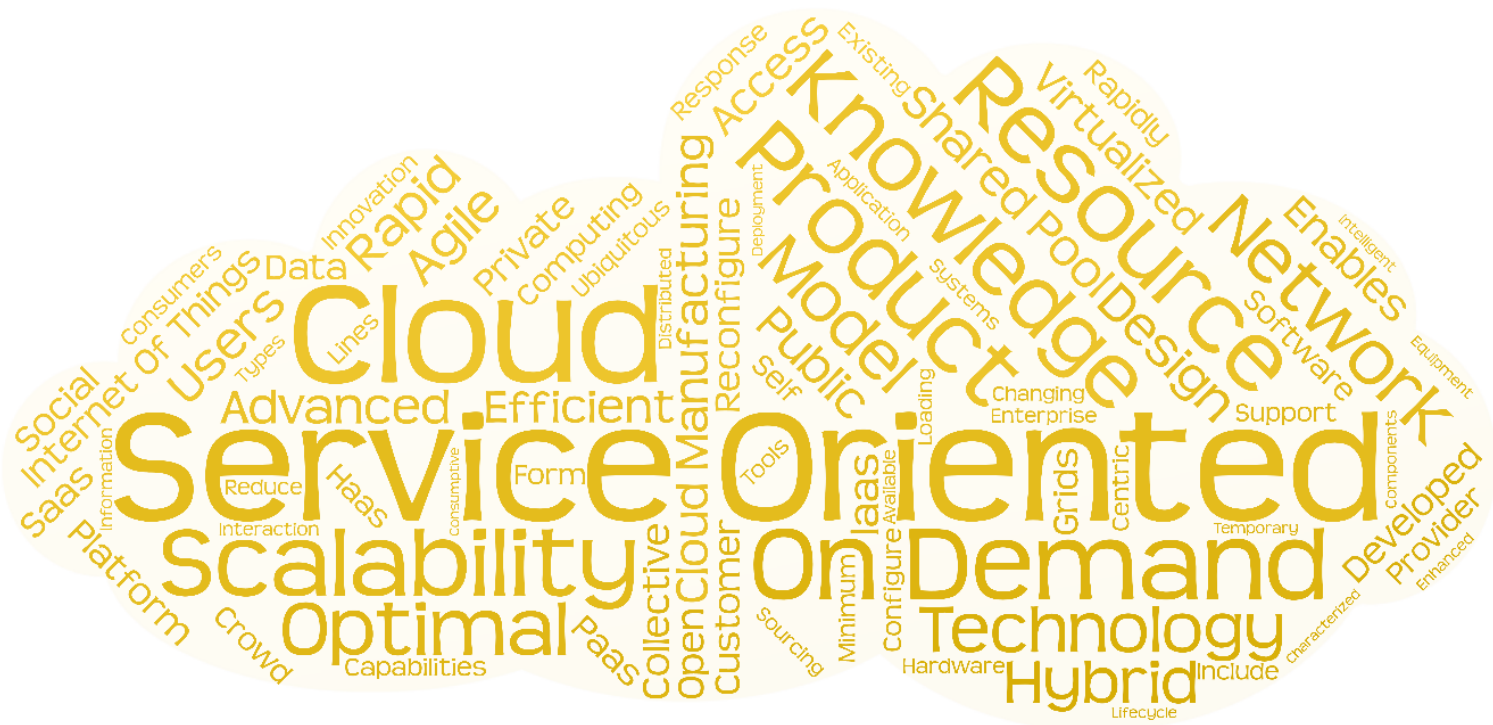

Fig. 1. Cloud manufacturing word cloud derived from $[14,15,26-29]$

\subsection{Key characteristics of cloud manufacturing}

Cloud manufacturing differentiates from other manufacturing paradigms because of several unique characteristics. Existing papers have explained in detail a selection of CM's characteristics or listed them without explanation [14, 28]. This paper complies all fundamental characteristics and explains their meaning, application within a CM environment and the benefits they bring. This is necessary because defining the characteristics helps to provide a clearer understanding on how CM offers a sustainable manufacturing future.

Flexibility and scalability:

A major advantage of $\mathrm{CM}$ over traditional manufacturing systems is the scalability offered. By nature $\mathrm{CM}$ production lines are no longer fixed but temporary, allowing for the option of small or long production runs depending on the user and market demands [28, 31]. Users of manufacturing resources are matched to the nearest available and appropriate manufacturing resource provider depending on their need. These supply lines are highly reconfigurable, dynamic and agile giving CM the ability to adapt to unpredicted changes of circumstance. For the system to be agile when repurposing manufacturing resources across any number of sites, a high level of automation across the supply lines shall be required. Section 3.3 explains what is meant by automation in a manufacturing context and how $\mathrm{CM}$ will further automatise the manufacturing process.

\section{Multi-tenancy:}

An important characteristic of $\mathrm{CM}$ is its ability to connect tenants intelligently for mutual benefit without human intervention. Each tenant is given some degree of control of their manufacturing cloud's architecture, e.g. adaptability of the user interface, without changing the application code [32]. The mechanisms by how multiple tenants and manufacturing clouds will interact is expanded on in section 2.3. 
An evaluation and reviewing system for users, like what is seen on Amazon, will be required to ensure quality of service provided. MFG.com is a real world example of a multi-tenant service that aims to quickly match manufacturers to suppliers [33]. It uses consumer generated ratings to ensure consumers are matched to suppliers that have demonstrated their products meets quality requirements, are safe and delivered on time.

Knowledge intensive, intelligent decision making tool:

Increasingly vast data sets are generated from data collected throughout the manufacturing process, but with varying degrees of utilisation. Currently the tendency is for the data to be compressed and archived for record keeping, and often only used for after the fact emergency analysis [34]. Cloud manufacturing acts as a mechanism to share this data within the manufacturing cloud so that useful manufacturing knowledge is extracted to support intelligent decision-making algorithms. Big data shall play a critical role in data collection and analysis [35]. As well as enhancing the process, data and manufacturing knowledge sharing across the manufacturing cloud is required for it to operate effectively. For example, four fundamental functions of $\mathrm{CM}$ that require knowledge support have been outlined as examples [14]:

1. Manufacturing resource and ability perception, connection, and virtualisation;

2. Cloud service description, match and search, aggregation, and composition;

3. Optimal allocation and scheduling;

4. Business workflow management.

However, the effectiveness of utilising data to improve manufacturing is dependent on the quality of the data collected. The data collected must be appropriate to the situation; therefore, calculated decisions must be taken to identify how the data is collected and the required granularity of that data.

\section{Intelligent on-demand manufacturing:}

Network manufacturing is a paradigm that has existed since 2000 [8]. It operates as a network of distributed manufacturing resources that are integrated on a joint manufacturing process. Where $\mathrm{CM}$ differs is in the method of communication between enterprises. Cloud manufacturing consists of a network of manufacturing resources that may operate automatically and/or independently via the decisions taken by the cloud platform. These manufacturing resources may be distributed within a single enterprise or shared across multiple enterprises.

On the cloud there will exist a 'pool' of shared manufacturing resources that is coordinated by the cloud platform enabling on-demand manufacturing. It must act intelligently, for example not overloading one manufacturing resource but utilising required resources in the most effective way to meet the user's requirements. Wu et al. illustrates this point effectively:

"If manufacturing resource " $A$ " is more heavily utilized than others in the network, yet the desired process can be performed by combining manufacturing resources " $\mathrm{B}$ " and " $\mathrm{C}$ ", the $\mathrm{CM}$ environment will automatically realize and capitalize upon this alternative to avoid excessive loading of manufacturing resource " $\mathrm{A}$ ". [28]

Manufacturing resource sharing and circulation are very important objectives in CM. It is a prerequisite of achieving on-demand and collaborative configuration of resources and services [20].

Manufacturing as a service:

A recurring theme from various $\mathrm{CM}$ definitions is the concept of manufacturing moving from production oriented manufacturing to service oriented manufacturing. Service oriented 
manufacturing integrates services throughout the product lifecycle, and allows producers a greater understanding of their product leading to a more efficient production process [36]. Cloud manufacturing achieves this by packaging manufacturing resources and capabilities as services, coordinated through the cloud on a pay-as-you-go scheme. Cloud manufacturing acts as centralised management platform for these services with a key goal of linking cloud consumers to cloud providers who can meet the product requirements of the consumer while maintaining cost, time and quality constraints. Cloud computing is currently operated as a service model and has an architecture split into three layers, Software as a Service (SaaS), Platform as a Service (PaaS) and Infrastructure as a Service (laaS) [15, 32]. Extending this concept to CM Tao et al. explains how the CM environment is enabled by the creation of Manufacturing Cloud Services (MCSs) [14]. Manufacturing resources and capabilities are virtualised and categorised, before being sorted into an appropriate manufacturing cloud. These services are then sold through the cloud on a pay-as-you-go scheme, offering greater flexibility to manufacturers than traditional fixed contacts.

\subsection{Cloud manufacturing frameworks, architectures and implementation}

Since CM's inception in 2010 there can be seen numerous proposed architectures for its implementation. Two similar initial proposals focused on a layer hierarchal framework for a possible structure of CM's architecture $[14,15]$. As research has progressed, this layer structure has been varied from three layers to twelve depending on the detail and depth the authors have undertaken $[27,29,37,38]$. Common to these proposals is the issue of identifying and virtualising manufacturing resources and capabilities. These are encapsulated in the cloud as services to be managed though a centralised intelligent platform. To provide real time control of these manufacturing services they are connected by utilising IloT technologies. This forms the bottom part of the layered framework. The middle section is then concerned with managing the cloud services. It is the backbone of the system and has a variety of duties to maintain and operate the cloud such as: scheduling, matching users with providers, quality control of services, remote monitoring of resources, fee calculation, evaluation, optimisation of process, etc. The higher layers of the framework are the application layers, which act as a portal through which cloud users interface with the system. Cloud users can communicate their individual needs and request various manufacturing cloud resources. A crucial feature of all the proposed frameworks is that knowledge is shared across the entire system and cloud security is constant and robust. A simplified, concise model of common features is presented in Fig. 2.

To understand how the $\mathrm{CM}$ architecture would be implemented, it is important to define the cloud users and their roles. There are commonly three defined roles, although the exact nomenclatural of each role varies. These are the cloud consumer, cloud provider and cloud operator [14, 15, 26, 29]. Cloud consumers and cloud providers have the obvious roles of one is utilising the cloud services for manufacturing purposes and one is providing these services. The cloud operator manages the use, performance, and delivery of cloud services as well as negotiating the relationship between cloud providers and cloud consumers. This role is sometimes split to involve a fourth cloud user known as a cloud carrier, which acts as the intermediary that provides connectivity and transport to enable exchange of services between consumers and providers [39]. Although it has been noted that one user may perform two or more of these roles [26], the implications of this on the possible manufacturing clouds and their business models has only recently been explored [23, 40]. Guo developed four possible models from different combinations of relationships between these users and the roles within the manufacturing cloud [23]. It was noted that the manufacturing cloud system design would be directly affected depending on the desired relationship between cloud users. 


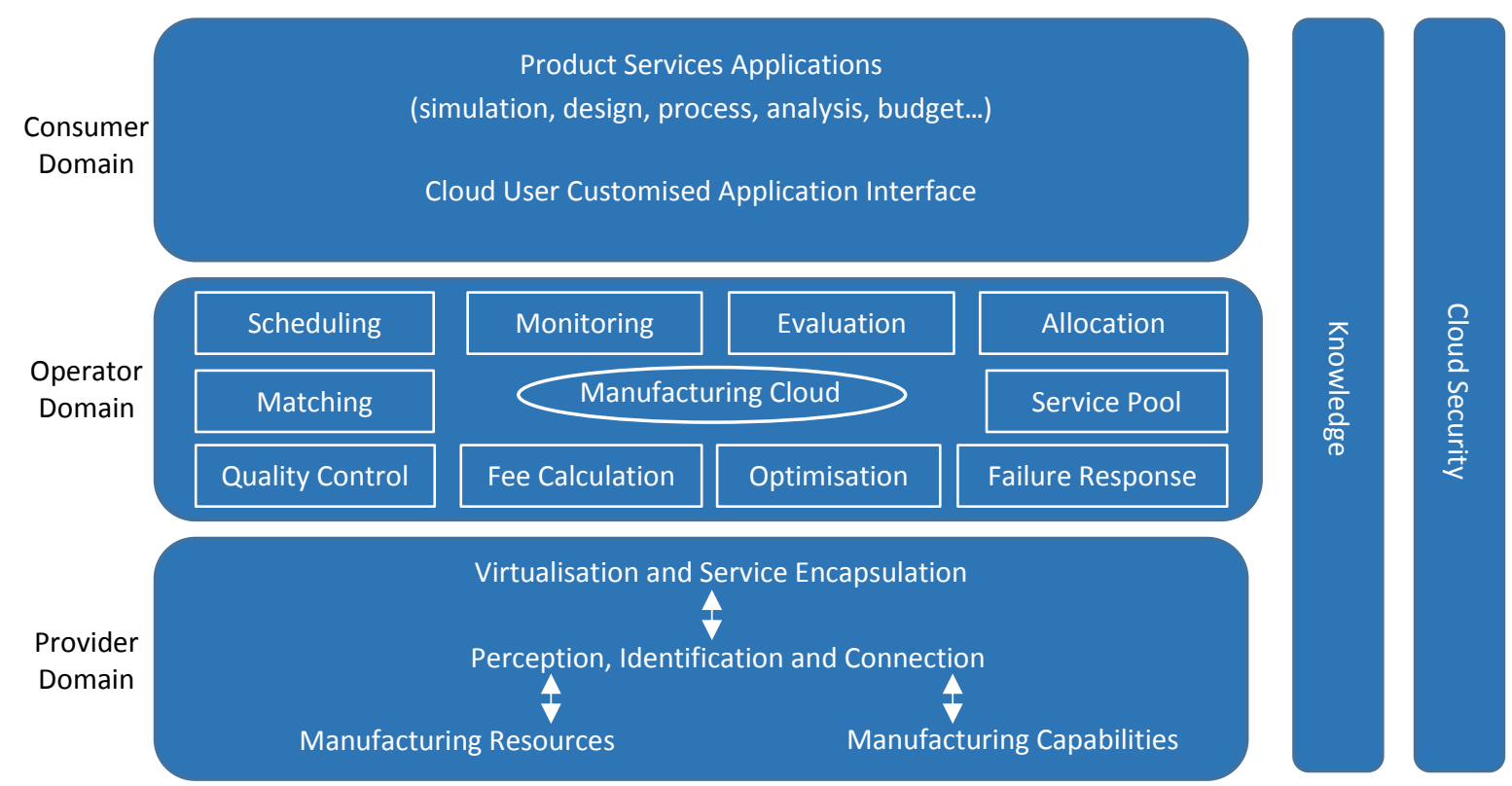

Fig. 2. Cloud manufacturing architecture adapted from [14, 15]

The current literature on CM's architecture broadly agrees on an overview for the framework and has instead moved focus onto how the system may be implemented. Part of that involves fully defining each layer and how it functions. Recent research has tried to achieved this by first defining an architecture, containing similar elements to those previously proposed, before breaking down each layer individually into flow charts to demonstrate how they would operate in practice [37].

The mechanism through which users shall interface depends on the manufacturing cloud deployment model. The manufacturing cloud has four potential deployment models: private, public, community and hybrid [15, 27, 41]. A private cloud would contain a single tenant's data and information and would provide services specific within that enterprise. By being private within an enterprise it allows security of data, with the exception of hacking. Multiple tenants who have a common interest may share certain knowledge or resources for mutual gain through the community cloud. On the public cloud manufacturing resources and capabilities and data is shared and managed by a third party and is the platform by which tenants from various backgrounds shall be able to interact with each other. Hybrid clouds consist of multiple external and internal clouds. An enterprise may have to utilise all four versions depending on the tasks.

Early research focused on single, isolated manufacturing clouds; however, for CM to be successful it will require the integration of multiple manufacturing clouds [42]. A hybrid manufacturing cloud allows enterprises to create multiple cloud models (public, private and community) depending on their business goals [43]. It provides a flexible and open environment that breaks down the barrier between organisations to allow for sharing of resources between enterprises, but it does not present a comprehensive method to integrate separate enterprises' manufacturing clouds. A hybrid integration framework for multiple manufacturing clouds was developed to enable users to find the most appropriate services across multiple manufacturing clouds, through a third party CM platform [21]. Similarly, a further system model has been considered where multiple 'cloud terminal subsystems' are connected to a 'cloud platform subsystem' [23]. The cloud terminal system is based on the enterprise information system. Industrial Internet of Things technologies collect information of enterpriser's information elements and provide an interconnection data interface with the cloud platform. Furthermore, it is responsible for integrating the manufacturing resources and manufacturing capabilities of the enterprise into the cloud platform for remote access and control. It would act as an 
enterprise's individual manufacturing cloud. The cloud platform subsystem acts as a big data management centre responsible for the convergence, integration, distribution, monitoring and operation management of the various manufacturing cloud services provided by the connected enterprises. It also provides the human-computer interface. By splitting the $\mathrm{CM}$ system into various cloud terminals and a cloud platform, Guo helps to demonstrate how multiple enterprises may possibly operate within the CM architecture [23].

\subsection{Case studies of cloud manufacturing's application}

As the research into $\mathrm{CM}$ has expanded, two directions have emerged. Broadly speaking, academia have recently been focusing on the interpretation and analysis of $\mathrm{CM}$, using case studies that demonstrate different applications of $\mathrm{CM}$. A selection of the recent case studies from the literature is presented in Table 2. These have been chosen because they demonstrate $\mathrm{CM}$ application in various sectors, each highlighting different $\mathrm{CM}$ characteristics. How and why $\mathrm{CM}$ is used is briefly summarised, and the main positive outcomes from the $\mathrm{CM}$ approach are detailed. All the case studies demonstrate how CM may achieve the optimal solution, as defined by the author. However, no one case study reached an optimal solution, and further work has been suggested for each in order to reach a more complete solution.

The focus in industry has been on developing a $\mathrm{CM}$ architecture, as seen from examples from the industry leaders. Siemens has developed a cloud platform called 'MindSphere' that interlinks physical products and production facilities with digital data, enabling innovative solutions and getting products onto the market faster, better and more efficiently [44]. Similarly, Plex Manufacturing Cloud delivers production control, inventory management, supply chain management, and more [17]. IBM has the IBM Watson IoT, which mines the influx of data from an IloT manufacturing process to make businesses more cognitive [45]. Industry has directed some application of CM, which is utilising manufacturing clouds to monitor and manage IloT manufacturing systems within an enterprise. These examples deliver partially enabling technologies but are not true CM systems. Cloud manufacturing has further capabilities made possible from sharing of manufacturing resources and capabilities which enable innovative, sustainable solutions. 
Table 2

Selected cloud manufacturing case studies from the literature

\begin{tabular}{|c|c|c|c|c|}
\hline $\begin{array}{l}\text { Case study summarised } \\
\text { and sector, where } \\
\text { given, highlighted }\end{array}$ & $\begin{array}{l}\text { Cloud manufacturing } \\
\text { features the study } \\
\text { highlights }\end{array}$ & $\begin{array}{l}\text { Outcomes from CM } \\
\text { approach }\end{array}$ & $\begin{array}{l}\text { Future work required suggested by this paper and } \\
\text { Further work suggested by original authors in italics }\end{array}$ & $\begin{array}{l}\text { Author and } \\
\text { year }\end{array}$ \\
\hline $\begin{array}{l}\text { A proposed service } \\
\text { optimisation } \\
\text { configuration method } \\
\text { for manufacturing } \\
\text { assembly lines. Sector } \\
\text { not specified, but model } \\
\text { would apply to any } \\
\text { sector with assembly } \\
\text { lines. }\end{array}$ & $\begin{array}{l}\text { Manufacturing as a } \\
\text { service: Servitisation of } \\
\text { manufacturing resources. } \\
\text { Intelligent on-demand } \\
\text { manufacturing: Optimal } \\
\text { configuration method of } \\
\text { services based on grey } \\
\text { relational analysis. }\end{array}$ & $\begin{array}{l}\text { CM was used for } \\
\text { proactive discovery of } \\
\text { manufacturing resources } \\
\text { through servitisation. } \\
\text { Method finds satisfying } \\
\text { solutions with low cost } \\
\text { and time consumption. }\end{array}$ & $\begin{array}{l}\text { Method does not consider environmental impacts when } \\
\text { determining optimal solution. } \\
\text { Real-time manufacturing information processing } \\
\text { mechanism between bottom-level manufacturing } \\
\text { machines and manufacturing cells. Batch volume of } \\
\text { manufacturing tasks should be taken into account in the } \\
\text { optimal selection of service composition. }\end{array}$ & $2016,[20]$ \\
\hline $\begin{array}{l}\text { A model to assess the } \\
\text { sustainable } \\
\text { manufacturing } \\
\text { capability (SMC) of } \\
\text { industrial robots (IR), } \\
\text { used in discrete } \\
\text { manufacturing. }\end{array}$ & $\begin{array}{l}\text { Decision making tool: } \\
\text { Sustainability of different } \\
\text { manufacturing routes } \\
\text { analysed. }\end{array}$ & $\begin{array}{l}\text { Cloud platform was able } \\
\text { to predict energy } \\
\text { consumption of IR for } \\
\text { assessing their capability } \\
\text { to perform a } \\
\text { manufacturing task. }\end{array}$ & $\begin{array}{l}\text { Limited to predicting the energy consumption of a } \\
\text { manufacturing process only to the energy consumed by } \\
\text { the IRs. Could be expanded to include other energy } \\
\text { outputs, such as transport of materials. } \\
\text { More factors should be considered to comprehensively } \\
\text { describe the SMC of IRs, such as collaboration safety } \\
\text { with human. }\end{array}$ & $2017,[46]$ \\
\hline $\begin{array}{l}\text { An adaptive artificial } \\
\text { bee colony algorithm is } \\
\text { used for decision } \\
\text { making on the cloud } \\
\text { service selection and } \\
\text { composition. }\end{array}$ & $\begin{array}{l}\text { Flexibility and scalability, } \\
\text { and decision making } \\
\text { tool: Feasibility of } \\
\text { different manufacturing } \\
\text { routes analysed. }\end{array}$ & $\begin{array}{l}\text { Model includes the } \\
\text { geographical location or } \\
\text { services when quantifying } \\
\text { the quality of service. }\end{array}$ & $\begin{array}{l}\text { A limitation is the long time required by complex } \\
\text { models. Extra computing power can be accessed } \\
\text { through CM. Further work should investigate balancing } \\
\text { cost of increased computational power with time saved. } \\
\text { Integration of artificial neural networks for the } \\
\text { definition of maximum cycle number }\end{array}$ & $2015,[47]$ \\
\hline $\begin{array}{l}\text { A cloud platform is } \\
\text { established for the } \\
\text { polymer industry for }\end{array}$ & $\begin{array}{l}\text { Decision making tool: } \\
\text { Data mining for optimal } \\
\text { solution. Computer-aided }\end{array}$ & $\begin{array}{l}\text { The knowledge-based } \\
\text { intelligent searching } \\
\text { algorithm finished in } 10\end{array}$ & $\begin{array}{l}\text { Case study only explored how CM can be applied to the } \\
\text { design phase. Further work should investigate how }\end{array}$ & 2016, [22] \\
\hline
\end{tabular}




\begin{tabular}{|c|c|c|c|c|}
\hline $\begin{array}{l}\text { optimising the } \\
\text { processes of blending } \\
\text { polymer materials. }\end{array}$ & $\begin{array}{l}\text { process design based on } \\
\text { CM. } \\
\text { Flexibility and scalability: } \\
\text { Flexible CM system built } \\
\text { that responds to } \\
\text { customers' demands. }\end{array}$ & $\begin{array}{l}\text { minutes compared to the } \\
5 \text { hours it took by } \\
\text { traditional methods. }\end{array}$ & $\begin{array}{l}\text { effectively the model would respond to different } \\
\text { customer demands during production phase. } \\
\text { N/A }\end{array}$ & \\
\hline $\begin{array}{l}\text { Public cloud } \\
\text { manufacturing system } \\
\text { for SMEs in } \\
\text { manufacturing } \\
\text { equipment industry in } \\
\text { South China. }\end{array}$ & $\begin{array}{l}\text { Multi-tenancy and } \\
\text { intelligent on-demand } \\
\text { manufacturing: } \\
\text { Performs intelligent } \\
\text { multidimensional } \\
\text { matching of consumers to } \\
\text { providers. }\end{array}$ & $\begin{array}{l}\text { Enterprises can respond } \\
\text { to market requirements } \\
\text { more quickly and cost } \\
\text { effectively than before. } \\
\text { Crowdsourcing model } \\
\text { demonstrates how CM } \\
\text { can be used to develop } \\
\text { innovative designs. }\end{array}$ & $\begin{array}{l}\text { Exploring how enterprises' private clouds will integrate } \\
\text { with public cloud. } \\
\text { To apply CM to more manufacturing applications. } \\
\text { To investigate business models for CM. }\end{array}$ & $2015,[37]$ \\
\hline $\begin{array}{l}\text { A CM architecture is } \\
\text { developed to optimise } \\
\text { the production logistics } \\
\text { of a paint making } \\
\text { company. }\end{array}$ & $\begin{array}{l}\text { Manufacturing as a } \\
\text { service: Real-time } \\
\text { monitoring of resources } \\
\text { using IloT. } \\
\text { Decision making tool: } \\
\text { Enterprise resource } \\
\text { planning }\end{array}$ & $\begin{array}{l}\text { The cloud coordinates an } \\
\text { improved schedule } \\
\text { resulting in logistics } \\
\text { waiting costs and } \\
\text { overtime working } \\
\text { reductions of } \\
\text { approximately } 50 \% .\end{array}$ & $\begin{array}{l}\text { Resources monitored are all manually controlled. } \\
\text { Therefore lacking real-time execution of management } \\
\text { system. } \\
\text { Expand qualitative solution presented in paper to the } \\
\text { quantitative stage to achieve more accurate application } \\
\text { results. }\end{array}$ & 2016, [48] \\
\hline $\begin{array}{l}\text { A CM system is } \\
\text { constructed within a } \\
\text { conglomerate which } \\
\text { designs and } \\
\text { manufactures multi- } \\
\text { disciplinary complex } \\
\text { products in the discrete } \\
\text { manufacturing sector. }\end{array}$ & $\begin{array}{l}\text { Manufacturing as a } \\
\text { service and multi- } \\
\text { tenancy: Sharing of } \\
\text { manufacturing recourses } \\
\text { and capabilities through a } \\
\text { hybrid framework } \\
\text { integrating multiple } \\
\text { manufacturing clouds. }\end{array}$ & $\begin{array}{l}\text { Cloud manufacturing links } \\
\text { enterprises so institutions } \\
\text { learn to employ core } \\
\text { competences of other } \\
\text { institutions. This allows } \\
\text { them to focus on their } \\
\text { own core competences. }\end{array}$ & $\begin{array}{l}\text { Proposed system does not consider what information } \\
\text { should be private between different institutions or } \\
\text { intellectual property issues when designing new } \\
\text { products. } \\
\text { Domain-specific demands and characteristics of } \\
\text { business collaboration to design efficient collaborative } \\
\text { algorithms for any industry. Service-oriented } \\
\text { architecture based integration methods of } \\
\text { manufacturing resources and capabilities. }\end{array}$ & $2016,[21]$ \\
\hline
\end{tabular}




\section{Cloud manufacturing as a route to sustainable manufacturing}

From understanding CM's characteristics and applications, the methods and opportunities for how $\mathrm{CM}$ may be used to enhance sustainability is explored. Three pillars of sustainability were formalised for future sustainable development during the 2002 World Summit, these are economic development, social development and environmental protection [49]. These pillars often come into conflict with one another, as seen during the $20^{\text {th }}$ century where economic development for a better quality of life was favoured at the expense of the environment [50].

\subsection{Sustainability drivers and barriers}

Manufacturers have traditionally focused on just the economic aspect of sustainable development [50], whereas external drivers are now forcing companies to adopt environmental sustainable development strategies. Five key drivers have been identified pushing manufacturers towards overall sustainability which are: (1) legislation; (2) customer demands; (3) shortage of natural resources; (4) population increase; and (5) business competitiveness.

Despite these drivers, there are still numerous barriers in the way of sustainable manufacturing. These barriers can be sorted into four categories: (1) policy and market barriers; (2) financial and economic barriers; (3) technical and information barriers; and (4) managerial and organisational barriers [51]. From these barriers a lack of information and lack of allocated resources (time and human) are the most common given responses preventing companies adopting sustainable strategies [52]. This lack of information includes areas such as environmental impact and expertise knowledge. Lack of allocated resources will also include materials alongside time and human.

\subsection{Cloud manufacturing enabling collaboration for innovative designs}

Cloud manufacturing offers various solutions to the barriers preventing sustainable manufacturing. Two of the barriers highlighted by companies is a lack of expertise knowledge available within an enterprise and ease of access to quantitative environmental impact information of manufacturing processes [52]. A characteristic of $\mathrm{CM}$ is that knowledge and data is collected, stored and shared throughout the supply chain. Those sharing data can determine what data, how much data, and with whom this data is shared. During the initial stages of a partnership between cloud users limited data sharing may take place, but as the relationship progresses data sharing may increase with trust.

A new concept of 'Social Manufacturing' has recently emerged where manufacturers and individuals work together in the production of physical goods [53]. Cloud manufacturing complements this concept through its ability to crowdsource information and simulate innovative designs [37]. The CM platform can be used to match developers to relevant expertise, and ubiquitous access to design information [26, 27]. In the long term this should increase the amount of collaborative designs leading to innovative solutions to sustainable manufacturing problems [54]. Intellectual property barriers will arise here and deciding what information should be made available and what should remain private will be a challenge but overall, CM benefits from a share-to-gain philosophy [31].

\subsection{Greater automation from the adoption of cloud manufacturing systems}

Automation is required to enable some of CM's characteristics. Automation is defined as "any activity that is performed by a machine or an algorithm with no human involvement" [55]. Automation of the production stage of manufacturing is not new. For $\mathrm{CM}$ to be effective it will need to integrate with other emerging technologies such as smart factories and IloT, which work to further increase automation in the production stage. Recently the automatisation of the planning and scheduling of manufacturing activities has gained more attention as an alternative route to furthering the 
sustainability of manufacturing processes [55]. Lean manufacturing, just in time manufacturing, supply chain management, and other manufacturing paradigms are previous attempts at this [56]. Cloud manufacturing stands above these paradigms because of the unprecedented level of data integration across the enterprise. This will allow for the identification of previously unseen optimisation routes and implementation from a $\mathrm{CM}$ centralised management centre, ensuring factory floor and business decisions are simultaneously made in relationship to one another.

One advantage from the automatisation of the supply chain is greater process agility. Market turbulence, volatility and unpredictability are some of the biggest challenges facing manufacturers and agile supply chains are becoming vital in order to respond quickly to these changes [57]. Cloud manufacturing supply chains are highly reconfigurable, because of the increased emphasis on modularity [54]. This is achieved by the packaging of manufacturing resources and manufacturing capabilities as services sold through the manufacturing cloud. The flexibility and scalability offered allows $\mathrm{CM}$ to respond to market changes quicker due to the shorter supply contracts and provides greater customisation of products increasing the economic sustainability of manufacturing processes. For $\mathrm{CM}$ to be able to manipulate manufacturing resources it will rely on IloT technologies integrated throughout the supply chain [48]. The cloud platform intelligently schedules the manufacturing process, meaning that the providers of $\mathrm{CM}$ services no longer must actively search for contacts. These features enable $\mathrm{CM}$ to become proactive rather than reactive when responding to market volatility. How CM will determine the optimal configuration and proactive resource discovery is a major challenge preventing its deployment and is the subject of much of the present research [20,58,59]. As enterprises begin to rely on a variety of service providers for different stages of the product cycle, methods to quantify and guarantee a quality of service will need to be developed [47].

Furthermore, advanced planning and scheduling shall reduce manufacturing time, energy and material waste. As seen from section 2.4 an extensive amount of the current literature has focused on developing methods by which the optimal manufacturing route can be discovered and implemented by $\mathrm{CM}$. As a route to process sustainability this has great potential for minimisation of all types of manufacturing waste. However, what is yet to be explored is how CM can be harnessed for waste valorisation opportunities.

\section{Application to process engineering manufacturing}

The literature up until now has focused on defining $\mathrm{CM}$ and constructing possible architectures for how CM may be applied to industry. In the literature, the limitations and benefits of CM have been discussed in context to the overall manufacturing industry. However, what has yet to be touched upon is that within manufacturing two distinct branches exist "discrete manufacturing" and "process manufacturing" [60]. Although there are several similarities between the two, there also exists significant differences. The application and benefits of CM to discrete manufacturing stand out because of discrete manufacturing's assembly lines and their high customisability. For example, the automobile industry already offers consumers the option to customise their cars during production. It is simpler to visualise a network of separate factories making unique components to be assembled at one location and being coordinated through a centralised system, or alternatively 3D industrial printers producing specialised products unique to each customer. These concepts are harder to visualise for process manufacturing, as the product produced is not an assembly of different components but rather a combination of raw materials or "ingredients".

\subsection{Difference between discrete and process manufacturing}

The differences between discrete manufacturing and process manufacturing is summarised in Table 3. The fundamental cause of these differences is within the nature of the manufacturing process itself. 
In discrete manufacturing a specific quantity of material moves between different processing equipment as it is cut and assembled together [60]. Whereas in process manufacturing, raw or waste materials flow through the process undergoing thermal, chemical and/or biochemical conversion. The product(s) is then separated out from the process stream. There can be overlap within the two branches of manufacturing. For example, in the food industry a bar of chocolate is a distinct item or product but results from process manufacturing.

The methods by which CM enhances sustainability in manufacturing is outlined in section 3 and these are broadly applicable to both discrete and process manufacturing. There also exists opportunities for applying $\mathrm{CM}$ to process manufacturing scenarios. However, with the research on $\mathrm{CM}$ focusing on discrete manufacturing examples (section 2.4), these opportunities have yet to be fully explored. This paper shall focus on two aspects where process manufacturing differs from discrete manufacturing, including the impact on process manufacturing performance. The two aspects are:

1. Waste generation and management;

2. Feedstock variability.

Table 3

Differences between discrete and process manufacturing

\begin{tabular}{|c|c|c|}
\hline & Process manufacturing & Discrete manufacturing \\
\hline $\begin{array}{l}\text { Manufacturing } \\
\text { practice }\end{array}$ & $\begin{array}{l}\text { Thermal and/or } \\
\text { biochemical/chemical conversion } \\
\text { of raw materials into final } \\
\text { product and by-products, which } \\
\text { typically are then extracted and } \\
\text { purified. }\end{array}$ & $\begin{array}{l}\text { Assembling parts and components into } \\
\text { a final product. }\end{array}$ \\
\hline Example industries & $\begin{array}{l}\text { Chemicals, food and drink, paint, } \\
\text { polymer, pharmaceutical, steel, } \\
\text { fast moving consumer goods } \\
\text { (FMCG). }\end{array}$ & $\begin{array}{l}\text { Automobiles, computers and } \\
\text { electronics, furniture, textile, } \\
\text { construction. }\end{array}$ \\
\hline \multirow[t]{2}{*}{ Quality control } & $\begin{array}{l}\text { Product typically must meet a } \\
\text { specified purity and yield. }\end{array}$ & $\begin{array}{l}\text { Quality is assured via inspection of a } \\
\text { statistical determined amount of } \\
\text { products for defects. }\end{array}$ \\
\hline & $\begin{array}{l}\text { During start up or shut down } \\
\text { product produced will not meet } \\
\text { these specifications and only } \\
\text { wasteful material is produced. }\end{array}$ & $\begin{array}{l}\text { Start up and shut down is } \\
\text { instantaneous and makes no difference } \\
\text { to product quality. }\end{array}$ \\
\hline \multirow[t]{2}{*}{ Feedstocks } & $\begin{array}{l}\text { Raw materials, often in } \\
\text { liquid/gaseous form. }\end{array}$ & Discrete units/bill of materials. \\
\hline & $\begin{array}{l}\text { Variation in feedstock } \\
\text { characteristics often present. }\end{array}$ & $\begin{array}{l}\text { Feedstock characteristics often } \\
\text { constant. }\end{array}$ \\
\hline \multirow[t]{2}{*}{ Products } & $\begin{array}{l}\text { Product is typically produced as a } \\
\text { bulk quantity item, such as } \\
\text { chemicals, polymers, } \\
\text { pharmaceuticals, food stuffs, } \\
\text { rather than distinct items. }\end{array}$ & $\begin{array}{l}\text { Distinct items, such as automobiles, } \\
\text { toys, tools etc. }\end{array}$ \\
\hline & $\begin{array}{l}\text { Quantified by volume/mass of } \\
\text { product. }\end{array}$ & \\
\hline
\end{tabular}




\begin{tabular}{lll}
\hline & & $\begin{array}{l}\text { Quantified by number of items } \\
\text { produced. }\end{array}$ \\
\hline Waste produced & $\begin{array}{l}\text { Liquid and solid waste streams } \\
\text { containing potentially valuable } \\
\text { material residue, co-products, } \\
\text { recoverable heat or water. }\end{array}$ & Defects, unused parts, cuttings etc. \\
\hline
\end{tabular}

\subsection{Application of collaborative design and greater automation to process manufacturing}

Traditionally manufacturing has been a linear model (make, use, dispose). However, due to diminishing resources and legislative drivers, a circular approach is being encouraged [6]. Process manufacturing has a unique opportunity for development of innovative designs because of its ability to manipulate the manufacturing route to increase the potential to valorise waste and by-product streams. One such innovative solution has been developed by Lindhurst Engineering Itd called $\mathrm{H}^{2} \mathrm{AD}$ Micro AD. The $\mathrm{H}_{2} A D$ is a hybrid of anaerobic digestion (AD) and microbial fuel cell technology [61]. It reduces pollutants in wastewaters and generates energy that can be utilised by the manufacturer to directly reduce energy bills. Unlike traditional $A D, H^{2} A D$ operates on the microscale meaning each batch takes only three days and can be retrofitted to existing small manufacturing plants making it suitable for Small and Medium Enterprises (SMEs). This technology may be modified to treat wastewater streams from a variety of industries. By using $\mathrm{CM}$ as platform to share historical $\mathrm{H}^{2} \mathrm{AD}$ performance data, manufacturers may utilise this data when modifying the $H^{2} A D$ unit for treating a previously untested industry's wastewater.

Both discrete and process manufacturing benefit from the application of CM for automated supply chains, as detailed in section 3.3. However, the application of automation for process manufacturing is different to discrete manufacturing. Discrete manufacturing has focused on automating manufacturing lines, by the introduction of autonomous machines used to assemble products instead of human labour [62]. Process manufacturing requires a high degree of automation, monitoring and control, and were among the first industries to be automated [63]. Traditional automation involves sophisticated process control which operates based on data collected from temperature, pressure, flow rate and level sensor measurements from an individual process plant. Cloud manufacturing could help to make more informed decisions relating to remote processing plant's operations, through the collection and analysis of data from multiple plant sources. This is facilitated by CM's characteristic of being a centralised repository for multi-site data $[23,64]$.

Automation in the process manufacturing industry is progressing by the development of advanced, commercial sensors and analytics [65-67]. These sensors can collect data not previously available, enabling manufacturers to identify alternative sustainable manufacturing routes. An example is the development of a multi-sensor system based upon ultraviolet optical fluorescence imaging and ultrasonic acoustic sensors for Clean-In-Place (CIP) optimisation within the food and drink industry [68]. Existing CIP processes are time intensive and waste large amounts of energy, water, and chemicals as they operate on a worst-case scenario. This system aims to take the data recorded and use a machine learning approach to determine the optimal time to stop cleaning, saving both time and materials [68]. The savings made in time are significant, as the food industry spends on average $20 \%$ of the day cleaning which could instead be utilised for production [69]. Cloud manufacturing enables the data collected to be analysed remotely requiring no additional expertise within the enterprise. This is particularly beneficial to SMEs who may not have the resources for data analytics 
within the enterprise. Caution is needed that some element of human integration with safety and quality control practices is retained, rather than a complete reliance on artificial models. For instance, with the CIP example switching between producing different food products on the same manufacturing plant may result in the production of pathogens the sensors are not able to detect.

\subsection{Cloud manufacturing for waste valorisation}

The waste hierarchy was first introduced into European waste policy by Directive 75/442/EEC, emphasising the importance of waste minimisation, and the protection of the environment and human health [70]. It has been updated in Directive 2008/98/EC to introduce a five-step waste hierarchy that states which waste management methods have priority based on environmental impact and extended beyond waste minimisation to reuse, recycling and recovery (Fig. 3) [5]. Preventing and reducing the amount of waste generated is always the first option in optimising the sustainability of a manufacturing process. This is an option available to both discrete and process manufacturing. However, regardless of how effective this stage is, the manufacturing environment will always produce some waste. The circular economy model treats this waste generated as a resource to feed back into the economy, rather than a waste to be disposed of. It takes a cyclical view where waste is constantly fed back into the economy, and there is minimal input of new material entering the system.

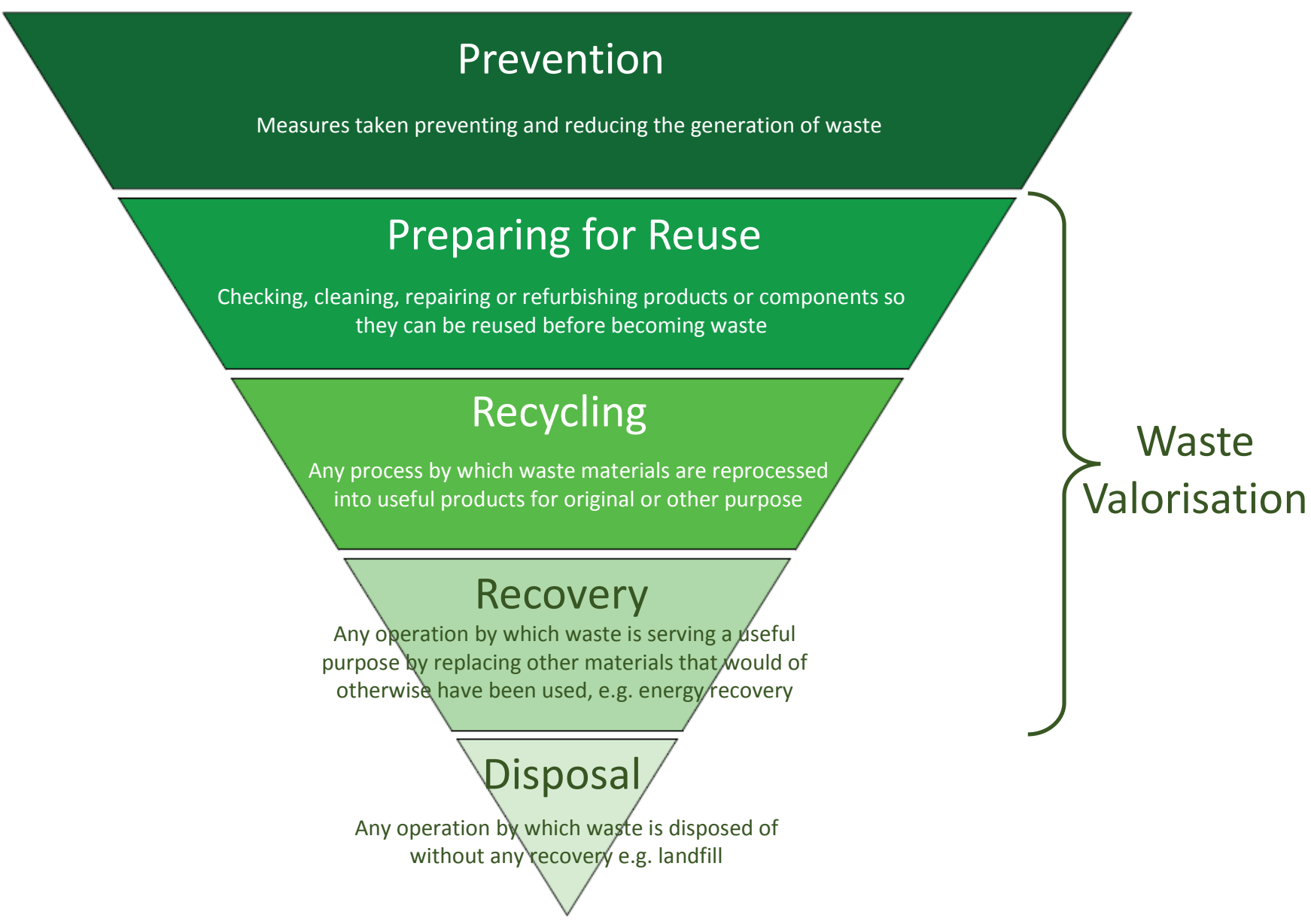

Fig. 3. Waste hierarchy adapted from Directive 2008/98/EC [5]

Discrete manufacturing produces mainly solid waste generated from defects, off cuttings, and unused parts during manufacturing [71]. Hence discrete manufacturing has limited waste valorisation opportunities, with instead a focus on waste minimisation and remanufacturing, which can be 
enhanced by $\mathrm{CM}$ [54]. Waste valorisation refers to industrial processing activities aimed at reusing, recycling, or recovering useful products or sources of energy from waste.

There are currently three waste valorisation strategies, geared towards: (1) production of fuel and/or energy to replace fossil fuels; (2) production of high-value chemicals from residues; and (3) production of other useful material(s) [72]. Process manufacturing generates a wide range of solid, liquid and gas waste streams that contain significant quantities of valuable material, which may be recovered by the application of these strategies. Taking the food manufacturing industry as an example, its waste contains valuable compounds such as fats, proteins, bioethanol etc, which can be converted to soaps, rubber, fuels and more [73]. Furthermore, through biological, chemical and thermal processes, such as $A D$ and pyrolysis, biogases and other gases can be produced as fuel or used for energy generation. Garcia-Garcia et al. effectively demonstrates how the waste hierarchy principles can be applied to selecting the most sustainable waste valorisation technology for treating food manufacturers' waste [73].

British Sugar's Wissington sugar production site is an excellent example of a manufacturing process that would not be economical sustainable without waste valorisation [74]. By reusing, recycling and recovering waste, British Sugar generates eleven co-products ranging from topsoil and animal feed to bioethanol and tomatoes [74]. This extensive waste valorisation has made British Sugar's Wissington factory one of the most efficient sugar factory in Europe and is an excellent example of the benefits of waste valorisation within process manufacturing [75].

Process manufacturing waste has a wide range of waste valorisation routes available [76-78]. As noted, a key characteristic of CM is the collection and sharing of data and expertise knowledge, which aids in the ability of $\mathrm{CM}$ to make intelligent, sustainable decisions. Cloud manufacturing can be used to evaluate the most sustainable valorisation waste method from this data. For example, in the production of olive-oil, solid waste pomace is produced. Traditionally pomace is a feedstock for production of pomace-olive oil and pomace wood, but there now exists several higher value products it can be converted to, including biomolecules, dyes and cosmetic products [79]. The flexible supply lines inherent within $\mathrm{CM}$ and real time analysis of market prices means that $\mathrm{CM}$ can be used to identify the most cost effective waste treatment method and co-orientate its implementation. This would be advantageous to SMEs who may not have their own waste treatment infrastructure on site but pay to have their waste taken away and treated by an external company.

As a multi-tenancy platform, $\mathrm{CM}$ can be used to match different cloud users together. Connecting and enhancing communication between local manufacturers will help to identify current inefficient waste treatment methods and identify local sustainable alternatives. As an example, CM may identify an alternative feed source for a process from another local manufacturer's waste, replacing a nonrenewable source. This would be a preferred treatment option because it is higher up the EU waste hierarchy. However, it is important to recognise the importance of geographical location of manufacturing and waste treatment plants when constructing the manufacturing cloud [23]. The most sustainable waste treatment option may not be local, and the transportation of waste is both environmentally and economically costly. Therefore, there must be a balance between the best treatment option and feasibility to maximise overall sustainability. Cloud manufacturing also has the capability to identify suitable transportation routes and match suppliers and customers. It has the potential to utilise wasted transportation capacity, maximising the economic return for the transporter and decreasing $\mathrm{CO}_{2}$ transport emissions from manufacturing. Cloud manufacturing could support a business model similar to the taxi service Uber where multiple consumers with a similar journey route share a single vehicle. This is an expansion on the optimisation of supply chain scheduling CM offers, as discussed in section 3.3. 
Real time monitoring of the composition of waste streams is required for $\mathrm{CM}$ to make intelligent decisions on how the waste should be utilised. For example, pyrolysis (the thermal decomposition of biomass in the absence of oxygen) is highly dependent on the moisture content of the feedstock [80]. At higher moisture contents, high levels of water are produced and at lower levels there is a risk that the process only produces dust instead of oil, char or gas [80]. Online measurement of the waste can feed back into the drying stage to ensure appropriate levels of drying takes place. Alternatively, in the design phase $\mathrm{CM}$ can be used to both access and analyse large volumes of stored process data to determine trends in moisture content of biomass waste. The conclusion may be reached to use the alternative biomass valorisation process hydrothermal carbonisation which operates in the presence of supercritical water. Hydrothermal carbonisation benefits from high moisture contents and may be judged to be the more sustainable route if a high moisture content trend is discovered [81]. Furthermore, if the waste stream is to be advertised through $\mathrm{CM}$ as a feedstock it will require its composition and properties to be defined to inform on the waste valorisation technology and where waste is considered a feedstock, considerations of the variability on the waste composition is required.

Process manufacturing has the potential for a wide range of waste valorisation methods. Cloud manufacturing can support this through three main methods:

1. It can be used as a decision tool for deciding the most sustainable waste valorisation routes, ideally the highest up the waste hierarchy to meet EU Directive;

2. It can identify and coordinate alternative waste valorisation routes if they prove to become more sustainable;

3. Cloud manufacturing can link and coordinate local supply chains to reuse waste streams as a feedstock, with minimal treatment.

\subsection{How cloud manufacturing increases process resilience}

Process manufacturing is reliant on process conditions that define how the feedstock is utilised and how equipment is operated in order to deliver a product at a predefined specification. The process conditions include but are not limited to process streams composition, temperature, pressure and flowrates. The nature of process manufacturing products having to meet a specific specification relies on a need for strong process resilience. There exist examples of process manufacturing goods being recalled because they did not meet specifications or face fines for breach of environmental limits [82]. This is also present in discrete manufacturing, though it is less common due to it being less susceptible to variations in manufacturing conditions. The current practise to ensure process resilience is to account for variability in the design stage. Section 4.4 will explore how CM enhances current methods, as well as offering new solutions.

A crude but effective method of ensuring process resilience is to design the manufacturing plant to operate within the design envelope. The design envelope of a system refers to its specified requirements that, if satisfied, would enable the system to perform as intended in the operational environment [83]. This has the disadvantage of increased capital and operating costs. If the design envelope is underestimated the process plant shall fail, with a best case scenario resulting in off spec product and at worst a fatal incident [84]. Certain process conditions are outside the control of the engineers and technicians. Feedstock supply lines and composition is a critical process condition that is subject to external variables. As manufacturers move away from non-renewable sources towards waste and biomass feedstocks this will become an even greater challenge for future engineers [85]. This is again an example of how the large knowledge and data store available through CM would benefit the design stage of manufacturing. Advanced data analysis techniques available on the manufacturing cloud would be able to predict and model to a higher degree of accuracy the future 
trends of feedstock variations [86]. This allows for the design envelope to be reduced while still maintaining a safe operating range and increasing economic sustainability. During the plant operation, the reconfigurable supply lines inherent within $\mathrm{CM}$ will allow for easy identification and implementation of alternative local feedstock sources. This can help mitigate the risk of using waste and biomass sources as feedstocks in process manufacturing operations. Furthermore, advanced data analysis of historical manufacturing data can help designers gain a better understanding of the process and products. It is more effective to ensure quality in the products by building quality into the design rather than continued testing and adjustment of critical process parameters.

It has been highlighted that a current barrier in process manufacturing that prevents enterprise-wise optimisation is the lack of data integration and supply chain coordination across the enterprise and between enterprises [87]. Qin explains how data in process manufacturing is currently collected based on a hierarchy structure [34]. The bottom levels are the monitoring of equipment via sensors that happen virtually instantaneously. At the process level there is regular monitoring of process control data (temperature, pressure and flowrate), with product quality more often sampled irregularly and maybe off site. The top level is the customer feedback data. There is a significant time lag between the data at higher levels and its implementation to the manufacturing resources. Cloud manufacturing architecture is a data-centric system that ensures data is made available across all manufacturing and business levels [23]. Rather than having a hierarchy structure, it shall be circular with data from across the supply chain feeding back into the manufacturing process. This shall reduce the time lag and better inform on the process to find the optimal configuration.

Cloud manufacturing will need to rely on big data technologies to achieve this. Big data is the collection and analysis of vast volumes of data throughout the manufacturing process to reveal trends, patterns and process optimisation routes [86]. Currently process manufacturing already collects a large amount of data from process control systems but it is not fully utilised, often only used for emergency after the event analysis [34]. Cloud manufacturing's reliance on advanced sensing technologies and widespread communication technologies will increase the amount and variety of data generated in manufacturing systems [88]. Data gathered from the manufacturing process could be used for

1. data mining and modelling of time series data for trend spotting and forecasting;

2. online use for real time operations optimisation and intelligent decision making;

3. offline troubleshooting as a valuable tool for continuous improvement.

Multivariate statistical approaches have been the recent favourite choice for data analysis, but new developments in machine learning and data mining offer opportunities to gain value from large, unclean data sets [34]. Machine learning advances in closed-loop optimisation may be used by CM to continuously optimise process control online. Houben and Lapkin summarise the recent advances in automatic optimisation of process conditions and explain how machine learning can build selfoptimising algorithms [89]. By achieving tight process control the process plant will be able to operate closer to steady state process conditions despite variations in external conditions, lowering the energy and material consumption. Enterprises often lack effective analytic tools or computational power to get any real meaning out of this data. The service nature of $\mathrm{CM}$ allows enterprises to hire either extra computational processing power or outsource their data analysis to specialist data analysis companies on a pay-as-you-go business model.

\subsection{Examples of cloud manufacturing's application to process manufacturing}

To further reinforce how $\mathrm{CM}$ may be applied to process manufacturing, examples are presented in Table 4 for each of CM's unique characteristics applied to different industries. 


\section{Table 4}

Examples of cloud manufacturing's application to process manufacturing industries.

Cloud manufacturing Application to process manufacturing Industrial examples

characteristic

Flexibility and

scalability
Continued monitoring of real time economic data to ensure the optimal manufacturing route.
Two adsorbents may be used for the recovery of $\mathrm{CO}_{2}$ from flue gas by pressure swing adsorption, Zeolite and Activated Carbon [90]. During the lifetime of the plant these adsorbents may need to be replaced. Cloud manufacturing can be utilised to reassess which adsorbent is most sustainable, using the most recent economic and performance data.

$\begin{array}{ll}\text { Knowledge intensive } & \begin{array}{l}\text { Utilise data across the supply chain to } \\ \text { build an artificially intelligent (AI) } \\ \text { algorithm to optimise process } \\ \text { conditions. }\end{array}\end{array}$

More accurate pricing of feedstocks, wastes and products.

\section{Multi-tenancy}

Co-ordination of multiple manufacturers' waste streams within geographical region.

Sharing Al algorithms
The active component for all anti-malarial drugs is artemisinin and is harvested from a plant called Artemisia annua [91]. When the plant is harvested impacts the manufacturing plant's optimal process conditions to improve the artemisinin recovery [91]. Utilising IloT technologies during growing and harvesting, CM system would integrate this data downstream to more accurately predict the required process conditions.

When a batch of potatoes arrives at a factory for the production of crisps, samples are taken to assess the quality of the potatoes and determine their value [92]. These tests can prove unreliable and new tests which utilise artificial neural networks are being developed [92]. By uploading these results to the manufacturing cloud, CM can be used to track various deliveries and coordinate accurate payments to each potato supplier. Brewer Spent Gain (BSG) in a wet solid waste from the brewery process which has a wide variety of valorisations options [93]. Individually microbreweries do not produce enough BSG to make it feasible to valorise. However, CM could be used to coordinate the collection of BSG to enable one of these technologies to be successfully implemented by a third party.

An algorithm created to optimise the treatment of a wastewater by anaerobic digesters may be sold through CM to the benefit of the initial developer and other water treatment companies. The algorithm would be built upon valuable performance data that the developer would not want its competitor accessing. Cloud manufacturing acts 
as an impartial third party able to utilise performance data to retrain and optimise the algorithm, without disclosing eithers manufacturers' data.

On-demand

Customisation of products

Responding to changes in customer's demands

Manufacturing as a

service
Outsourcing expertise

Outsourcing parts of the supply chain
The data generated by wearable 'lifestyle' technologies has the potential to

revolutionise the method by which patients are diagnosed [94]. This data may also be used to determine an individual's required dosage. Cloud manufacturing would act as a platform sharing data between manufacturers, doctors and patients to enable personalised medicine.

Demand side management is the modification of consumer demand of energy, and is used to attempt to limit the peak demand on an electrical grid [95]. However, the energy sector is facing the challenge of trying to utilise unreliable renewable energy sources and an increase in customer demand [95]. One of the largest consumers of energy are process manufacturers. Cloud manufacturing could help limit the demand on the grid during peak times by increasing the communication between energy providers and manufacturers to schedule the most energy demanding processes when there is minimum demand on the electrical grid.

Affordable IloT technologies are currently been developed aimed at automating the brewery process in microbreweries, generating new data sets [96]. Microbreweries have limited employees and do not have in-house data analyst to effectively make use of this data. Cloud manufacturing can be used to outsource their data analysis needs.

In the dairy industry whey is a by-product of cheese production, and has a wide variety of valorisation options [97]. Large scale cheese manufacturers normally valorise the whey on-site. Small independent cheese makers have limited capital to invest in these technologies to valorise on site, and instead the whey is treated as a waste. Through CM they can outsource the valorisation of the whey to either waste management companies or local large scale cheese manufacturers. 


\section{Limitations and future research directions}

The literature to date has identified limitations that prevent widespread adoption of $\mathrm{CM}$ by manufacturers from the discrete manufacturing perspective. These limitations being identified as data sharing, cyber security, integration of technologies, modelling of material flow, and integrating existing systems within a CM system [42, 48, 64, 98]. However, these limitations are also relevant to process manufacturing, for instance data sharing among process manufacturers (Section 5.1). There are also limitations applicable only to process manufacturing, which are processing plant security and characterisation of process streams (Section 5.2 and 5.3 respectively). Potential limitations may also be industry specific within process manufacturing, when the cloud user is an SME (Section 5.4), though $\mathrm{CM}$ will also afford unique opportunities to SMEs [38].

\subsection{Data sharing among process manufacturers}

The current barriers obstructing free flow of data between enterprises have already been thoroughly discussed [98]. However, data sharing is important to elucidate on from a process manufacturing perspective. Large data sets are required to train and optimise the Al algorithms that CM will use [99]. As previously stated, the large process manufacturers were the first industries to be automated and thus have generated large quantities of data [63]. However, new companies and SMEs may not have access to enough data to build, train and validate the required mathematical models. Cloud manufacturing can overcome this by sharing either already built algorithms or manufacturing data from similar processes to act as a starting point in the construction of these algorithms. Manufacturers are naturally reluctant to share their data between competitors. A framework needs to be developed that will allow the manufacturing cloud to act as a third party to utilise another company's manufacturing data and/or models, without disclosing this information to the competing company. A pricing mechanism will also be required to assess and judge the value of the data used.

\subsection{Processing plant security}

Unlike discrete manufacturing, process manufacturing involves the thermal, chemical and or biochemical conversion of materials to products at temperatures and pressures which can be hazardous. Some industrial reactions are exothermic and there is the potential for runaway reactions if not controlled. This is a danger unique to process manufacturing industries and there are many reported cases where this has occurred and resulted in causalities [100]. Process plant safety has evolved in past 20-30 years, moving from corrective to preventive. The emphasis is on designing out hazards and where this is not possible, process control systems are used to monitor temperatures and pressures within a reactor ready to shut off if they reach dangerous levels. However, as with any use of online systems, the potential for hacking needs evaluating with risk mitigation. For process manufacturing this is a legitimate consideration and one not relevant to discrete manufacturing.

As manufacturing resources are increasingly controlled remotely there exist safety concerns protecting these control systems from malicious attacks. The "Aurora Project", performed by Idaho National Laboratory in 2007, first demonstrated the dangers from cyber criminals hacking into a process plant's control system to manipulate and ultimately destroy physical systems [101]. Sophisticated cyber-attacks on control systems are becoming more frequent, resulting in the need for advanced cyber-security systems [102].

\subsection{Characterisation of process streams}

As highlighted in section 4.1, a fundamental difference between discrete and process manufacturing is the variability in process manufacturing's process streams. Be these feedstocks, wastes or byproduct streams. For $\mathrm{CM}$ to be able to make intelligent decisions, it will require the characterisation 
of these process streams in real time, compared to the current practise of infrequent sampling and analysis off line [34]. This is because the Al algorithms that will be developed to support CM's decisionmaking ability will rely on real time data to ensure they are continuously learning. These Al algorithms must be capable of learning, so they can continually work to optimise all aspects of the manufacturing process and adapt to variations in process streams. Process manufacturing is currently limited from further automation by the development of commercially affordable sensors capable of characterising process streams in real time.

\subsection{Barriers preventing SMEs adopting new technologies}

Small and medium enterprises are considered the backbone of a country's economy, providing the majority of all new jobs and vital for stimulating economic growth [103]. Within process manufacturing certain industries have a strong SME portfolio, for instance the food and drink industry [104]. The wealth of SMEs are seen as a benefit because of the high value artisan products they produce, for example bakery products, cheeses and craft beers. There is strong growth within these industries as customers demand quality over quantity and are prepared to pay for this. The brewery industry in the UK is an example of this, observing a large increase in microbreweries despite a downward trend in beer consumption [105]. However, SMEs can struggle to adapt to external market forces and to make the next step in expanding their business due to a lack of expertise and resources. This is where CM shows great potential in enabling SMEs to overcome these barriers [38].

Small and medium enterprises can be slow in adopting new technologies, which are shown to improve revenue. They do not always have either the capital to invest in new technologies, or the expertise or guidance necessary to successfully implement them. The countries where SMEs have been most successful in adopting new technologies are countries which have coherent Government strategies in place to support them, for example in Germany (Industrie 4.0), China (Made in China 2025), and the USA (America Makes) [106]. This has resulted in higher levels of productivity (output per worker) in these countries over others, like the UK, which have lower levels of adoption [106]. If CM is to follow this example there needs to be a strong, coherent strategy in place to advice SMEs on how best to utilise CM for their needs.

\section{Future of Manufacturing}

Both government and academic literature agree that future manufacturing will evolve more sustainable manufacturing processes and business models radically different from those of today [56, 107]. A growing global population and the effects of climate changes shall cause volatility in supply chains, driving the development of manufacturing processes that are more resilient and require less material, energy, water and land inputs. Resource insecurity shall become a greater threat in regions like the EU where rare earth minerals are depleted and there is a heavy reliance on imports. This will force economies to rebalance towards a circular economy, where no waste is created but materials are instead reused, remanufactured, cascaded, recycled and recovered [108]. The global community is beginning to take active steps towards closing the loop and becoming a circular economy [109-111]. Advances in waste valorisation and remanufacturing technologies will bring society closer towards achieving this, and CM offers a route to facility and enhance the circular economy.

Increased communication between manufacturers and customers, coupled with on-demand manufacturing, enables greater customisation of products to meet individual customer's needs. Customisation allows consumers the ability to create more personalised products and research by Loughborough University shows consumers are willing to pay an additional $10 \%$ for this service [112]. Customisation has great marketing potential allowing for customisation of products that reflect the event of the day. To enable effective customisation, manufacturing process must become flexible and 
agile to respond to customers' demands in a timely manner. To provide customised products manufacturers need more diverse resources and manufacturing capabilities, which $\mathrm{CM}$ can provide [113].

Additive manufacturing has real potential for customisation. At present its main application is printing geometrical complex components for high-value products in the aerospace, high-end automotive and bio-medical sectors [12]. This is because it is currently much faster to mass produce products using traditional production lines than AM. However, as the technology improves, and greater value is placed on personalised products, AM will shape the size and distribution of future factories. In one possible scenario there will be a mix of large super factories producing complex products, and small local factories producing personalised domestic products [107]. In 2015 Amazon filed a patent for lorries carrying 3D printers that will take orders online and produce the finished product by the time it reaches the customers door [114]. Within the process sectors, AM of food and pharmaceuticals products have recently made progress in overcoming the unique challenges these industries face in using 3D printing products $[115,116]$. Additive manufacturing allows the product to be tailored for individual consumer's requirements. For example, there is research into the customisation of nutrition within 3D printed food products based on an individual dietary requirements for weight lost and further health benefits [117]. The application of CM is a feasible model to deploy large scale personalised AM [19, 118]. Cloud manufacturing supports increased communication between customers and manufacturers and may act as an interface for customers to upload their personalised requirements into the manufacturing process.

\section{Conclusion}

For the first time a detailed explanation of all of CM's key characteristics has been summarised. Recent case studies demonstrating the application of these characteristics in a CM system has been citied. The benefits and drawbacks of each study has been summarised, as well as the future work required to further develop these systems. Presented are examples of applying CM characteristics to process manufacturing industries. By understanding these characteristics and how they can be applied to manufacturing, it enabled the exploration of how $\mathrm{CM}$ may be used to enhance sustainability. Four key methods of how CM increases sustainability have been identified: (1) collaborative design; (2) greater automation; (3) increase in process resilience; and (4) enhanced waste reduction, reuse and recovery (see Fig. 4).

As resource scarcity increases and climate change disrupts global supply chains, there will be an everincreasing need for manufacturing processes that utilise waste valorisation strategies rather than relying on fresh material and energy inputs. As a model for implementing a circular economy approach in manufacturing, $\mathrm{CM}$ provides opportunities for both discrete and process manufacturing to improve sustainability. Cloud manufacturing research gained attention with the early models developed by Tao et al. and $\mathrm{Xu}$, and the application of $\mathrm{CM}$ for sustainable process manufacturing complements both these models $[14,15]$. 
Recent developments in technologies that are digitalising manufacturing have seen a rush of research into investigating the opportunities they offer. However, a framework for the infrastructure these different technologies shall operate within is currently lacking. Cloud manufacturing has the potential to act as an intelligent platform to interact remotely with the increasingly digitalised supply chain. This complete monitoring across the supply chain allows CM to identify, coordinate and implement opportunities for increased sustainability. This could not have been realised by the current manufacturing model where enterprises within a supply chain act with greater independence of each other. Before $\mathrm{CM}$ can be fully realised, examples of its operation in real world manufacturing models and the benefits it delivers will need to be demonstrated.

(1) Collaborative design: A critical barrier preventing sustainable manufacturing designs is the accessibility of environmental information and expertise knowledge within an enterprise. Cloud manufacturing operates on a multi-tenancy cloud platform that can crowdsource information and expertise to simulate the development of innovative sustainable designs. Process manufacturing has unique opportunities for new sustainable design from its ability to manipulate the manufacturing route to valorise waste and byproduct streams.

(2) Automation: Cloud manufacturing can perform real time analyses of manufacturing and market data to intelligently schedule and plan the manufacturing process. This allows for $\mathrm{CM}$ to optimise the manufacturing process in real time and coordinate its implementation across the supply lines from a centralised management centre. This reduces the manufacturing costs through minimising energy consumption, material waste and downtime. Process manufacturing will become further automated by the implementation of advanced sensors, allowing CM to develop intelligent models. These models help to identity and implement more sustainable manufacturing solutions.

(3) Waste valorisation: Process manufacturing waste has the potential for valorisation as it can contain valuable material residue, co-products opportunities, residual heat, and energy recovery. It is not always obvious which is the most sustainable waste valorisation route, and $\mathrm{CM}$ can be used as an intelligent decision making tool. $\mathrm{CM}$ can monitor functions in the composition of waste streams and market prices to identify and coordinate alternative waste valorisation routes if they prove to become significantly more sustainable. Furthermore, $\mathrm{CM}$ can coordinate local supply chains to reuse waste streams as a feedstock. From these methods, CM aligns with the circular economy vision perceiving waste as a valuable resource to be reused, recovered and regenerated.

(4) Process resilience: Process manufacturing systems are particularly susceptible to variations in process conditions, especially feedstock composition. Currently over engineering is the best method to ensure variations do not impact product quality. Advanced data analytic techniques offer the potential to gain better process understanding to ensure quality in the design of the system. As advanced IloT sensors are developed, this will provide $\mathrm{CM}$ with greater quantity and granularity of data meaning previously unidentifiably solutions can be implemented.

Fig. 4. Summary of how Cloud Manufacturing enables sustainable manufacturing 


\section{Acknowledgements}

The author (RLG) would like to acknowledge the support of Engineering and Physical Sciences Research Council (EPSRC) [grant number EP/K014161], Cloud Manufacturing - Towards Resilient and Scalable High Value Manufacturing. The author (OJF) would also like to acknowledge the University of Nottingham for his PhD scholarship. All authors would like to thank David Golightly of Nottingham University for his contributions and useful insights.

\section{Funding}

This work was supported by the Engineering and Physical Sciences Research Council (EPSRC) [grant number EP/K014161].

\section{References}

[1] World Trade Organization. World Trade Statistical Review 2016, https://www.wto.org/english/res e/statis e/wts2016 e/wts16 toc e.htm; 2016 [accessed 10/04/2017]

[2] HM Treasury. Budget 2011. The Stationery Office; London; 2011. p. 7-9.

[3] The World Bank. Manufacturing value added (\% GDP), http://data.worldbank.org/indicator/NV.IND.MANF.ZS; 2017 [accessed 10/04/2017]

[4] UNFCCC Secretariat. Adoption of the Paris Agreement. In: Conference of the Parties. United Nations. New York. 2015. p. 22-4.

[5] Directive 2008/98/EC of the European Parliament and of the Council of 19 November 2008 on waste and repealing certain directives. Off J Eur Union L 312/3 2008.

[6] Waste \& Resources Action Programme (WRAP). WRAP and the circular economy, http://www.wrap.org.uk/about-us/about/wrap-and-circular-economy; 2017 [accessed 13/04/2017] [7] Mahesh M, Ong SK, Nee AYC, Fuh JYH, Zhang YF. Towards a generic distributed and collaborative digital manufacturing. Robot Comput-Integr Manuf 2007;23:267-75.

[8] Montreuil B, Frayret JM, D'Amours S. A strategic framework for networked manufacturing. Comput Ind 2000;42:299-317.

[9] Mehrabi MG, Ulsoy AG, Koren Y. Reconfigurable manufacturing systems: Key to future manufacturing. J Intell Manuf 2000;11:403-19.

[10] Da Silveira G, Borenstein D, Fogliatto FS. Mass customization: Literature review and research directions. Int J Prod Econ 2001;72:1-13.

[11] Li BH, Zhang L, Wang SL, Tao F, Cao JW, Jiang XD, Song X, Chai XD. Cloud manufacturing: a new service-oriented networked manufacturing model. Comput Integr Manuf 2010;16:1-7.

[12] Gao W, Zhang Y, Ramanujan D, Ramani K, Chen Y, Williams CB, Wang CCL, Shin YC, Zhang S, Zavattieri PD. The status, challenges, and future of additive manufacturing in engineering. Comput Aided Des 2015;69:65-89.

[13] Ministry of Science and Technology of the People's Republic of China. National High-tech R\&D Program, http://www.most.gov.cn/eng/programmes1/200610/t20061009 36225.htm; 2016 [accessed 10/04/17]

[14] Tao F, Zhang L, Venkatesh VC, Luo Y, Cheng Y. Cloud manufacturing: a computing and serviceoriented manufacturing model. In: Proc Inst Mech Eng Part B-J Eng Manuf. 2011. p.1969-76.

[15] Xu X. From cloud computing to cloud manufacturing. Robot Comput-Integr Manuf 2012;28:7586.

[16] Manucloud-project.eu. Project Overview - The ManuCloud Project, http://www.manucloudproject.eu/; 2016 [accessed 05/12/16]

[17] Plex. Cloud ERP Software for Manufacturing, https://www.plex.com/; 2017 [accessed 10/04/2017]

[18] Qin J, Liu Y, Grosvenor R. A categorical framework of manufacturing for Industry 4.0 and beyond. Procedia CIRP 2016;52:173-8. 
[19] Liu KH, Zhong PS, Zeng QL, Li DM, Li SS. Application modes of cloud manufacturing and program analysis. J Mech Sci Technol 2017;31:157-64.

[20] Zhang YF, Xi D, Li R, Sun SD. Task-driven manufacturing cloud service proactive discovery and optimal configuration method. Int J Adv Manuf Technol 2016;84:29-45.

[21] Yang C, Shen WM, Lin TY, Wang XB. A hybrid framework for integrating multiple manufacturing clouds. Int J Adv Manuf Technol 2016;86:895-911.

[22] Qiu XM, He G, Ji X. Cloud manufacturing model in polymer material industry. Int J Adv Manuf Technol 2016;84:239-48.

[23] Guo L. A system design method for cloud manufacturing application system. Int J Adv Manuf Technol 2016;84:275-89.

[24] Zhou J, Yao X. Hybrid teaching-learning-based optimization of correlation-aware service composition in cloud manufacturing. Int J Adv Manuf Technol 2017;91:3515-33.

[25] Jin H, Yao X, Chen Y. Correlation-aware QoS modeling and manufacturing cloud service composition. J Intell Manuf 2017;28:1947-60.

[26] Schaefer D, Thames JL, Wellman RD, Wu DZ, Yim S, Rosen DW. Distributed collaborative design and manufacture in the cloud - motivation, infrastructure, and education. In: 2012 ASEE annual conference. 2012.

[27] Wu DZ, Thames JL, Rosen DW, Schaefer D. Enhancing the product realization process with cloud-based design and manufacturing systems. J Comput Inf Sci Eng 2013;13:0410041-04100414.

[28] Wu D, Greer MJ, Rosen DW, Schaefer D. Cloud manufacturing: Strategic vision and state-of-theart. J Manuf Syst 2013;32:564-79.

[29] Zhang L, Luo YL, Tao F, Li BH, Ren L, Zhang XS, Guo H, Cheng Y, Hu AR, Liu YK. Cloud manufacturing: a new manufacturing paradigm. Enterp Inf Syst 2012;8:167-87.

[30] WordArt. Word cloud generator, https://www.wordart.com; 2017 [accessed 10/04/2017] [31] Wu DZ, Greer MJ, Rosen DW, Schaefer D, Asme. Cloud manufacturing: drivers, current status, and future trends. In: Proceedings of the ASME 8th international manufacturing science and engineering conference. 2013. p.V002T02A3.

[32] Wang P, Gao RX, Fan ZY. Cloud computing for cloud manufacturing: benefits and limitations. J Manuf Sci Eng-Trans ASME 2015;137:

[33] MFG.com. About MFG.com, https://www.mfg.com/about-mfgcom; 2016 [accessed 01/03/2017]

[34] Qin SJ. Process data analytics in the era of big data. AIChE J 2014;60:3092-100.

[35] Zhong RY, Lan SL, Xu C, Dai QY, Huang GQ. Visualization of RFID-enabled shopfloor logistics big data in cloud manufacturing. Int J Adv Manuf Technol 2016;84:5-16.

[36] Gao J, Yao YL, Zhu VCY, Sun LY, Lin L. Service-oriented manufacturing: a new product pattern and manufacturing paradigm. J Intell Manuf 2011;22:435-46.

[37] Ren L, Zhang L, Tao F, Zhao C, Chai XD, Zhao XP. Cloud manufacturing: from concept to practice. Enterp Inf Syst 2015;9:186-209.

[38] Huang BQ, Li CH, Yin C, Zhao XP. Cloud manufacturing service platform for small- and mediumsized enterprises. Int J Adv Manuf Technol 2013;65:1261-72.

[39] Wu DZ, Thames JL, Rosen DW, Schaefer D. Towards a cloud-based design and manufacturing paradigm: looking backward, looking forward. In: Proceedings of the ASME international design engineering technical conferences and computers and information in engineering conference. 2012. p.315-28.

[40] Ren L, Cui J, Wei YC, Laili YJ, Zhang L. Research on the impact of service provider cooperative relationship on cloud manufacturing platform. Int J Adv Manuf Technol 2016;86:2279-90.

[41] Wu DZ, Rosen DW, Wang LH, Schaefer D. Cloud-based manufacturing: old wine in new bottles? In: Variety management in manufacturing: proceedings of the 47th CIRP conference on manufacturing systems. 2014. p.94-9.

[42] He W, Xu LD. A state-of-the-art survey of cloud manufacturing. Int J Comput Integr Manuf 2015;28:239-50.

[43] Lu YQ, Xu X, Xu J. Development of a hybrid manufacturing cloud. J Manuf Syst 2014;33:551-66. 
[44] Siemens. MindSphere - Siemens Cloud for Industry, http://w3.siemens.co.uk/services/uk/en/portfolio/plant-data-services/cloud-forindustry/pages/default.aspx\#; 2017 [accessed 10/04/2017]

[45] IBM. Journey to Industry 4.0 and beyond with IBM Watson loT for connected manufacturing, https://www.ibm.com/internet-of-things/iot-solutions/iot-manufacturing/; 2017 [accessed 10/01/2017]

[46] Zhao Y, Liu Q, Xu W, Wu X, Jiang X, Zhou Z, Pham DT. Dynamic and unified modelling of sustainable manufacturing capability for industrial robots in cloud manufacturing. Int J Adv Manuf Technol 2017;93:2753-71.

[47] Lartigau J, Xu XF, Nie LS, Zhan DC. Cloud manufacturing service composition based on QoS with geo-perspective transportation using an improved artificial bee colony optimisation algorithm. Int J Prod Res 2015;53:4380-404.

[48] Qu T, Lei SP, Wang ZZ, Nie DX, Chen X, Huang GQ. loT-based real-time production logistics synchronization system under smart cloud manufacturing. Int J Adv Manuf Technol 2016;84:147-64. [49] United Nations. Report of the world summit on sustainable development. Johannesburg. South Africa. New York. 2002. p. 14-5.

[50] Giret A, Trentesaux D, Prabhu V. Sustainability in manufacturing operations scheduling: A state of the art review. J Manuf Syst 2015;37:126-40.

[51] Shi H, Peng SZ, Liu Y, Zhong P. Barriers to the implementation of cleaner production in Chinese SMEs: government, industry and expert stakeholders' perspectives. J Clean Prod 2008;16:842-52.

[52] Bey N, Hauschild MZ, McAloone TC. Drivers and barriers for implementation of environmental strategies in manufacturing companies. CIRP Ann Manuf Technol 2013;62:43-6.

[53] Hamalainen $M$, Karjalainen J. Social manufacturing: When the maker movement meets interfirm production networks. Bus Horizons 2017;60:795-805.

[54] Bi ZM, Wang L. Manufacturing paradigm shift towards better sustainability. In: Li W, Mehnen J (editors.) Cloud manufacturing: distributed computing technologies for global and sustainable manufacturing, London: Springer London; 2013, p. 99-119.

[55] Monfared MAS, Yang JB. Design of integrated manufacturing planning, scheduling and control systems: a new framework for automation. Int J Adv Manuf Technol 2007;33:545-59.

[56] Esmaeilian B, Behdad S, Wang B. The evolution and future of manufacturing: A review. J Manuf Syst 2016;39:79-100.

[57] Jassbi J, Orio Gd, Barata D, Barata J. The impact of cloud manufacturing on supply chain agility. In: 2014 12th IEEE International conference on industrial informatics (INDIN). 2014. p.495-500.

[58] Yu C, Zhang W, Xu X, Ji Y, Yu S. Data mining based multi-level aggregate service planning for cloud manufacturing. J Intell Manuf 2015;1-11.

[59] Cao Y, Wang SL, Kang L, Li CS, Guo L. Study on machining service modes and resource selection strategies in cloud manufacturing. Int J Adv Manuf Technol 2015;81:597-613.

[60] Brandl D. Manufacturing control. In: Design patterns for flexible manufacturing, USA: ISA; 2007, p. 1-8.

[61] Micro H2AD. Welcome to H2AD, http://h2ad.org.uk/; 2017 [accessed 04/08/2017]

[62] Lastra JLM, Delamer IM. Ontologies for production automation. In: Dillon TS, Chang E, Meersman R, Sycara K (editors.) Advances in web semantics I: ontologies, web Services and applied wemantic web; 2008, p. 276-89.

[63] Canavas C. History of control and automation in chemical engineering. Chemie Ingenieur Technik 1995;67:709-17.

[64] Helo P, Suorsa M, Hao Y, Anussornnitisarn P. Toward a cloud-based manufacturing execution system for distributed manufacturing. Comput Ind 2014;65:646-56.

[65] Saguy IS, Singh RP, Johnson T, Fryer PJ, Sastry SK. Challenges facing food engineering. J Food Eng 2013;119:332-42. 
[66] Yeh ML, Chang CT. An automaton-based approach to evaluate and improve online diagnosis schemes for multi-failure scenarios in batch chemical processes. Chem Eng Res Des 2011;89:265266.

[67] Kumar A, Baldea M, Edgar TF. On optimal sensing and actuation design for an industrial scale steam methane reformer furnace. AIChE J 2016;62:3225-37.

[68] Simeone A, Watson N, Sterritt I, Woolley E. A multi-sensor approach for fouling level assessment in clean-in-place processes. Procedia CIRP 2016;55:134-9.

[69] Jude B, Lemaire E. How to optimize clean-in-place (CIP) processes in food and beverage operations. Schneider Electric White Paper; 2013.

[70] Directive 75/442/EEC of the European Parliament and of the Council of 15 July 1975 on waste Off J Eur Union L 442. 1975.

[71] Lieder M, Rashid A. Towards circular economy implementation: a comprehensive review in context of manufacturing industry. J Clean Prod 2016;115:36-51.

[72] Arancon RAD, Lin CSK, Chan KM, Kwan TH, Luque R. Advances on waste valorization: new horizons for a more sustainable society. Energ Sci Eng 2013;1:53-71.

[73] Garcia-Garcia G, Woolley E, Rahimifard S. A framework for a more efficient approach to food waste management. Int J Food Eng 2015;1:65-72.

[74] British Sugar. How our factory operates, http://www.britishsugarlearningzone.com/how-ourfactory-operates/\#; [accessed 16/02/2017]

[75] Short SW, Bocken NMP, Barlow CY, Chertow MR. From Refining Sugar to Growing Tomatoes. J Ind Ecol 2014;18:603-18.

[76] Ferrasse JH, Seyssiecq I, Roche N. Thermal gasification: a feasible solution for sewage sludge valorisation? Chem Eng Technol 2003;26:941-5.

[77] Briens C, Piskorz J, Berruti F. Biomass valorization for fuel and chemicals production: a review.

Int J Chem Reactor Eng 2008;6:

[78] Uçkun Kiran E, Trzcinski AP, Ng WJ, Liu Y. Bioconversion of food waste to energy: a review. Fuel 2014;134:389-99.

[79] Valta K, Aggeli E, Papadaskalopoulou C, Panaretou V, Sotiropoulos A, Malamis D, Moustakas K, Haralambous KJ. Adding value to olive oil production through waste and wastewater treatment and valorisation: the case of Greece. Waste Biomass Valorization 2015;6:913-25.

[80] Westerhof RJM, Kuipers NJM, Kersten SRA, van Swaaij WPM. Controlling the water content of biomass fast pyrolysis oil. Ind Eng Chem Res 2007;46:9238-47.

[81] Funke A, Ziegler F. Hydrothermal carbonization of biomass: a summary and discussion of chemical mechanisms for process engineering. Biofuels, Bioprod Biorefin 2010;4:160-77.

[82] Food Standards Agency. Food law prosecutions,

https://www.food.gov.uk/enforcement/prosecutions; 2017 [accessed 10/04/2017]

[83] Towler G, Sinnott R. Chapter 1 - introduction to design. In: Chemical engineering design (second edition), Boston: Butterworth-Heinemann; 2013, p. 3-32.

[84] Crowl DA, Louvar JF, Chemical process safety: fundamentals with applications, 3 ed., Pearson Education, Boston, MA, United States, 2011.

[85] Kenney KL, Smith WA, Gresham GL, Westover T. Understanding biomass feedstock variability. Biofuels 2013;4:11-127.

[86] Waller MA, Fawcett SE. Data science, predictive analytics, and big data: a revolution that will transform supply chain design and management. J Bus Logist 2013;34:77-84.

[87] Grossmann I. Enterprise-wide optimization: A new frontier in process systems engineering. AIChE J 2005;51:1846-57.

[88] Bao Y, Ren L, Zhang L, Zhang X, Luo Y. Massive sensor data management framework in cloud manufacturing based on Hadoop. In: IEEE 10th International conference on industrial informatics. 2012. p.397-401.

[89] Houben C, Lapkin AA. Automatic discovery and optimization of chemical processes. Curr Opin Chem Eng 2015;9:1-7. 
[90] Chue KT, Kim JN, Yoo YJ, Cho SH, Yang RT. Comparison of Activated Carbon and Zeolite 13X for CO2 Recovery from Flue Gas by Pressure Swing Adsorption. Ind Eng Chem Res 1995;34:591-8.

[91] Pilkington JL, Preston C, Gomes RL. Comparison of response surface methodology (RSM) and artificial neural networks (ANN) towards efficient extraction of artemisinin from Artemisia annua. Industrial Crops and Products 2014;58:15-24.

[92] Lopez-Juarez I, Rios-Cabrera R, Hsieh SJ, Howarth M. A hybrid non-invasive method for internal/external quality assessment of potatoes. European Food Research and Technology 2018;244:161-74.

[93] Xiros C, Christakopoulos P. Biotechnological Potential of Brewers Spent Grain and its Recent Applications. Waste Biomass Valorization 2012;3:213-32.

[94] Manufacturing vision for UK pharma. Medicines Manufacturing Industry Partnership; London; 2017.

[95] Hosseini Imani M, Niknejad P, Barzegaran MR. The impact of customers' participation level and various incentive values on implementing emergency demand response program in microgrid operation. International Journal of Electrical Power \& Energy Systems 2018;96:114-25.

[96] Gonzalez Viejo C, Fuentes S, Li G, Collmann R, Condé B, Torrico D. Development of a robotic pourer constructed with ubiquitous materials, open hardware and sensors to assess beer foam quality using computer vision and pattern recognition algorithms: RoboBEER. Food Research International 2016;89:504-13.

[97] Smithers GW. Whey and whey proteins-From 'gutter-to-gold'. International Dairy Journal 2008;18:695-704.

[98] Buckholtz B, Ragai I, Wang LH. Cloud manufacturing: current trends and future implementations. J Manuf Sci Eng-Trans ASME 2015;137:

[99] Himmelblau DM. Applications of artificial neural networks in chemical engineering. Korean Journal of Chemical Engineering 2000;17:373-92.

[100] Mannan MS, Reyes-Valdes O, Jain P, Tamim N, Ahammad M. The evolution of process safety: current status and future direction. Annu Rev Chem Biomol 2016;7:135-62.

[101] Liu CC, Stefanov A, Hong J, Panciatici P. Intruders in the Grid. IEEE Power and Energy Magazine 2012;10:58-66.

[102] You Y, Cho I, Lee K. An advanced approach to security measurement system. J Supercomputing 2016;72:3443-54.

[103] Airaksinen A, Luomaranta $H$, Alajääskö $P$, Roodhuijzen A. Statistics on small and medium-sized enterprises, http://ec.europa.eu/eurostat/statistics-

explained/index.php/Statistics on small and medium-sized enterprises; 2018 [accessed

05/01/2018]

[104] Defra. Food statistics pocketbook 2016. In: Department for Environment FaRA. The Stationary Office London. 2017. p. 12.

[105] Ellis V, Bosworth G. Supporting rural entrepreneurship in the UK microbrewery sector. British Food Journal 2015;117:2724-38.

[106] Maier J. Made smarter. Review 2017. In: Department for Business EIS. The Stationery Office. London 2017.

[107] Foresight. The Future of Manufacturing: a new era of opportunity and challenge for the UK. In: The Government Office for Science. London. 2013.

[108] Gregson N, Crang M, Fuller S, Holmes H. Interrogating the circular economy: the moral economy of resource recovery in the EU. Econ Soc 2015;44:218-43.

[109] European Commission. Report from the Commission to the European Parliament, the Council, the European economic and social committee and the committee of the regions on the implementation of the circular economy action plan. Brussels; 2017.

[110] Bowdish L. Trash to treasure: changing waste streams to profit streams. In: U.S. Chamber of Commerce Foundation. Washington 2016.

[111] Yong R. The circular economy in China. J Mater Cycles Waste 2007;9:121-9. 
[112] Dickens $P$, Kelly $M$, Williams J. What are the significant trends shaping technology relevant to manufacturing? In: Government Office for Science. Foresight. London. 2013.

[113] Yang C, Lan S, Shen W, Huang GQ, Wang X, Lin T. Towards product customization and personalization in loT-enabled cloud manufacturing. Cluster Comput 2017;20:1717-30.

[114] Apsley LK, Bodell Cl, Danton JC, Hayden SR, Kapila S, Lessard E, UhI RB, inventors; Amazon Technologies Inc, assignee. Providing services related to item delivery via 3D manufacturing on demand. United States patent US 20150052024. 2015 Feb 19.

[115] Prasad LK, Smyth H. 3D Printing technologies for drug delivery: a review. Drug Dev Ind Pharm 2016;42:1019-31.

[116] Izdebska J, Zolek-Tryznowska Z. 3D food printing - facts and future. Agro Food Ind Hi Tec 2016;27:33-7.

[117] Lipton JI, Cutler M, Nigl F, Cohen D, Lipson H. Additive manufacturing for the food industry. Trends Food Sci Tech 2015;43:114-23.

[118] Cerdas F, Juraschek M, Thiede S, Herrmann C. Life Cycle Assessment of 3D Printed Products in a Distributed Manufacturing System. J Ind Ecol 2017;21:S80-S93.

\section{Vitae}

Oliver Fisher earned a MEng in Chemical Engineering at the University of Nottingham (UK) in 2016. He is currently undertaking a PhD investigating intelligent resource use in process manufacturing at the University of Nottingham, and is a member of the Food, Water and Waste Research Group (FWW) in the Faculty of Engineering.

Dr Nicholas Watson has a MEng in Mechanical Engineering (University of Hull, 2005) and a PhD in Chemical Engineering (University of Leeds, 2010). From 2010 to 2014 he was a Post-Doctoral Research Assistant in the School of Food Science and Nutrition at the University of Leeds. In $2013 \mathrm{Dr}$ Watson became a chartered engineer and a member of the Institute of Mechanical. In 2014 he joined the University of Nottingham as an assistant professor in Chemical Engineering and became an Associated Member of the Institute of Chemical Engineers.

Rachel Gomes is an Associate Professor in Chemical and Environmental Engineering at the University of Nottingham, following an Anne McLaren Fellowship. Her research interests lie in sustainable resource utilisation towards wastewater treatment and process manufacturing. Rachel was selected in 2013 as an University Engineering Future Research Leader, and in 2014 became 1 of 20 on the Engineering and Physical Sciences Research Council Early Career Forum in Manufacturing Research and in the Top 40 under 40 Power List for the Analytical Scientist magazine in recognition of developing novel analytics to inform on wastewater treatment and chemical manufacture. 